\title{
A Dynamic Model of Optimal Creditor Dispersion
}

\author{
HONGDA ZHONG*
}

\begin{abstract}
Borrowing from multiple creditors exposes firms to rollover risk due to coordination problems among creditors, but it also improves firms' repayment incentives, thereby increasing pledgeability. Based on this trade-off, I develop a dynamic debt rollover model to analyze the evolution of creditor dispersion. Consistent with empirical evidence, I find that firms optimally increase creditor dispersion after poor performance. In contrast, cross-sectionally higher-growth firms can support more dispersed creditors. Frequent debt renegotiation limits firms' ability to increase pledgeability by having more creditors. Finally, holding a cash balance while borrowing from multiple creditors improves firms' repayment incentives uniformly across all future states.
\end{abstract}

MANY FIRMS BORROW FROM MULTIPLE creditors. ${ }^{1}$ Having more creditors risks coordination problems among them, making it more difficult for firms to restructure their debt. At face value, this seems to suggest that during bad times, firms should consolidate their creditors to facilitate renegotiation of distressed debt and mitigate bankruptcy. Surprisingly, however, empirical

\footnotetext{
*Hongda Zhong is with Department of Finance, the London School of Economics and Political Science. I am deeply indebted to my advisors, Philip Bond and Raj Singh, for their invaluable advice. For comments and suggestions, I thank Editors Wei Xiong and Bruno Biais; the Associate Editor; two anonymous referees; Murray Frank; Martin Szydlowski; Andrew Winton; Manuel Amador; Patrick Bolton; Jesse Davis; Jean-Paul Décamps; Zhiguo He; Lixin Huang; Martin Oehmke; Christopher Phelan; Yue Qiu; Michael Rebello; Haoxiang Zhu; and all seminar participants at the University of Minnesota, CKGSB, Indiana University, Johns Hopkins University, the University of Michigan, the University of Texas at Dallas, the University of Delaware, London School of Economics, the Chinese University of Hong Kong, the University of Reading, the University of Zurich, Tsinghua University, CEPR Annual Spring Symposium, the China International Conference in Finance, the European Finance Association, the Financial Intermediation Research Society, the Finance Theory Group Summer School, and the American Finance Association. Arthur Taburet and Dailin Yan provided excellent research assistance. The support of the Economic and Social Research Council (ESRC) is gratefully acknowledged (New Investigator Grant: ES/T003758/1). I have read The Journal of Finance disclosure policy and have no conflicts of interest to disclose.

Correspondence: Hongda Zhong, Department of Finance, the London School of Economics and Political Science, Room CON 2.17, Houghton Street, London WC2A 2AE, UK; e-mail: zhonghongda@gmail.com.
}

This is an open access article under the terms of the Creative Commons Attribution License, which permits use, distribution and reproduction in any medium, provided the original work is properly cited.

${ }^{1}$ See Ongena and Smith (2000b) for cross-country evidence and Harhoff and Körting (1998) for the borrowing patterns of small firms.

DOI: $10.1111 /$ jofi.12974

(C) 2020 The Authors. The Journal of Finance published by Wiley Periodicals LLC on behalf of American Finance Association 
evidence suggests the opposite-many firms increase the number of lenders they employ when their performance deteriorates (Farinha and Santos (2002), Rauh and Sufi (2010)). An obvious explanation for this pattern is that existing lenders refuse to throw more good money after bad, leaving firms no choice but to borrow from more creditors. However, one question remains: why would new creditors be willing to lend while incumbents are rushing for the exit?

To avoid the devastating consequences of coordination failures among creditors, many mechanisms are in place to promote the efficient renegotiation of distressed debt. However, easier debt renegotiation can potentially alter firms' repayment incentives, which affect their decisions to issue or refinance debt early on. Mechanisms that lead to ex post efficient debt renegotiation can also affect firms' ex ante choice of creditor dispersion, and as a result, the likelihood and outcome of renegotiation. Do such mechanisms always help prolong firms' life as intended?

To shed light on the questions above, creditor dispersion needs to be modeled as a dynamic variable that evolves endogenously, instead of a one-time choice. In this paper, I develop a parsimonious dynamic model in which a firm with insufficient internal resources must finance a long-term project by repeatedly rolling over short-term debt. The key friction is that the firm cannot commit to repay its debt at maturity, and thus needs incentives to do so. This lack of commitment power reduces the firm's credibility and limits the amount of debt capital it can raise. A dispersed creditor structure creates coordination problems, which following bad shocks can result in inefficient liquidation. With a good shock realization, however, the same coordination problems strengthen the firm's repayment incentives by making it harder for the firm to opportunistically hold up its creditors. The firm optimally readjusts the number of creditors in each period by trading off the risk of rollover failure against the benefit of better commitment to pay back its debt.

In contrast to prior literature, which relies largely on static models to examine creditor structure (e.g., Berglöf and Von Thadden (1994), Bolton and Scharfstein (1996), and Diamond (2004)), the dynamic debt rollover framework proposed here is arguably closer to reality. First, many firms use a staggered debt structure, and rollover failures can be costly (Almeida et al. (2012)). Perhaps more importantly, debt rollover itself is fundamentally a dynamic concept: the ability to roll over debt today depends on whether the firm's new creditors anticipate that they, in turn, can roll over their debt in the future, which again depends on whether creditors anticipate rollover to be possible even further in the future. Finally, Roberts and Sufi (2009a) show that $94 \%$ of loans with maturity longer than three years are renegotiated, and Roberts (2015) shows that a median renegotiated loan receives four renegotiations in its lifetime. Taken together, these empirical findings suggest that it is important to treat debt renegotiation as a dynamic process.

Despite the parsimony of the model, it generates a rich set of predictions, especially in the time series. First, my model delivers predictions on the number of creditors a firm has, as well as on the timing of decisions to seek more creditors or consolidate the existing ones. In the time series, I show that when 
firm performance deteriorates, the number of creditors increases. This is because the required amount of leverage increases endogenously when firms perform poorly. To support this higher leverage, firms must expand their pool of creditors so that future repayments are more credible. In the cross section, I investigate firms with exogenously different growth rates, and show that better firms with higher growth rates have larger debt capacity, which allows these firms to survive more rounds of renegotiation and therefore support more creditors. Hence, unlike in the time series, in the cross section, I find that faster growing firms can have more creditors on average.

The sharp contrast between the time-series and cross-sectional predictions reconciles seemingly contradictory empirical findings in prior work. Farinha and Santos (2002) and Rauh and Sufi (2010) find that both lending relationships and the composition of debt become more dispersed when firm performance deteriorates. In contrast, Houston and James (1996) find that firms with more relationship banks have higher asset growth compared to their singlebank counterparts. Through the lens of my dynamic model, the evidence in Farinha and Santos (2002) and Rauh and Sufi (2010) is consistent with the time-series prediction, whereas the Houston and James (1996) finding is consistent with the cross-sectional prediction.

In addition, the dynamic aspect of my model helps connect an important stream of theoretical literature with some stylized facts on the relation between borrowing costs and creditor dispersion. Many classic studies (e.g., Berglöf and Von Thadden (1994), Bolton and Scharfstein (1996), and Diamond (2004)) build on the idea that dispersed creditor structure commits a borrowing firm to pay back its debt. This channel implies that the required interest rate should be lower when the debt is more widely held, because the difficulty renegotiating with dispersed creditors makes repayments more credible. However, Petersen and Rajan (1994, 1995) empirically document a significant positive relation between the number of creditors and the cost of credit. My model suggests that although borrowing from more creditors does indeed help reduce the required interest rate, firms do so only when their performance deteriorates, driving up the observed interest rate in equilibrium.

The dynamic model also allows me to study how renegotiation frequency affects pledgeability - the maximum amount of debt capital a firm can raise. I find that when a firm can instantaneously renegotiate its debt, it can no longer pledge any value from a potential better state in the future, even with dispersed creditors to strengthen its commitment power. ${ }^{2}$ This result casts doubt on the traditional view in many two-period models that dispersed short-term debt alleviates the commitment problem stemming from renegotiation. In a fully dynamic world, when there is little time between two rounds of renegotiations, the fundamental is unlikely to change and thus highly persistent. To pledge the extra value from a better state in the following period, the firm needs to risk inefficient termination should the current (worse) state continue.

\footnotetext{
${ }^{2}$ Because potential debt renegotiation occurs in the model whenever debt matures, the finding can also be interpreted as one for debt maturity or rollover frequency.
} 
Because of the persistent fundamental, this termination risk becomes almost a certainty, whereas the benefit of realizing higher commitment power in the better state becomes vanishingly small. As a result, having dispersed creditors does not improve firms' ex ante pledgeability when renegotiation becomes frequent.

Finally, I present a novel role for cash. Together with multiple creditors, cash creates extra commitment power uniformly across all future states. This channel is different from the well-known Hart and Moore (1998) intuition for why firms borrow additional money and hold cash. In Hart and Moore (1998), where cash cannot be verified and hence cannot be seized by creditors upon liquidation, holding cash allows the firm to effectively buy back a fraction of the project (to reduce partial liquidation) when termination is relatively more inefficient. Unlike in Hart and Moore (1998), in my model cash can be seized by creditors. Consequently, when there is only one creditor, cash plays no role: the firm can pay down its debt with cash (simultaneously reducing the face value and the same amount of cash holding) to achieve the same outcome. In contrast, when there are multiple creditors, cash is part of the firm's statenoncontingent assets, and thus increases the reservation value for each creditor independent of the fundamental realization. A dispersed creditor structure therefore serves as a multiplier that magnifies the additional pledgeable repayment induced by the cash holding.

My paper is related to a large literature on coordination problems among dispersed creditors. Perhaps the most famous such problem is a bank (creditor) run. Diamond and Dybvig (1983) show that in a static setting, socially inefficient bank-run equilibria generally exist. Goldstein and Pauzner (2005) further characterize the probability of a bank run under a global game framework. He and Xiong (2012a) study dynamic runs on staggered corporate debt and show that a creditor's decision not to roll over maturing debt poses an externality on other creditors whose claims have not yet matured.

If borrowing from multiple lenders is subject to costly runs, why do firms continue this practice? Many scholars believe that such runs can be a disciplinary device that enhances ex ante efficiency. Berglöf and Von Thadden (1994) show that having multiple creditors specialize in lending at different maturities is a superior structure. Short-term creditors can impose externalities on long-term creditors at the debt renegotiation stage, thereby increasing firms' ex post repayment incentives. The threat of a bank run associated with dispersed demand deposits can incentivize financial intermediaries to return the proceeds to depositors (Diamond (2004)) and encourage depositors to acquire costly information about the banks (Calomiris and Kahn (1991)). Diamond (2004) demonstrates that dispersed creditors can solve the "passive lender" problem. A single lender with a large stake has little incentive to terminate a firm because doing so also hurts the lender. Without credible discipline, the firm may misbehave ex ante. In contrast, when there are multiple creditors, those that take disciplinary actions cast negative externalities on passive creditors, which increases incentives for lenders to be active ex post and in turn for the borrower to behave properly ex ante. More recently, 
Zetlin-Jones (2014) examines an environment with multiple intermediaries and dispersed depositors. These studies share the key insight that the threat of coordination failures associated with multiple creditors disciplines the firm and can potentially improve ex ante efficiency. However, these studies vary the number of creditors exogenously and therefore are silent on the question of when do firms endogenously change their creditor structure.

Several attempts have been made to endogenize the optimal number of creditors. To my knowledge, Bolton and Scharfstein (1996) is the first attempt and is closely related to my paper. In their model, the firm can strategically default and renegotiate debt even when it has the money to honor the repayment. Upon default, the creditor(s) can inefficiently sell the project to an outside investor. The benefit of having more creditors is to increase their collective bargaining power against the firm following a strategic default, so that creditors can extract higher repayments. However, in a fundamental-driven default, the stronger bargaining power of creditors also makes it less likely for them to find an outside investor, rendering default more costly. From a different angle, Detragiache, Garella, and Guiso (2000) study an economy in which bank financing can fail and the quality of the firm's project is unknown. Having multiple bank relationships offers more robust financing. However, when all relationship banks deny credit, having more banks makes the firm worse off because the uninformed market is more pessimistic about the firm's quality. Bris and Welch (2005) consider a "free-riding" problem that reduces an individual creditor's willingness to expend effort on debt collection. As opposed to the creditor-discipline channel, dispersed creditors reduce their collective bargaining power under the free-riding problem. A common feature of these papers is that they are all static: a one-time choice of creditor dispersion. I employ the idea in Bolton and Scharfstein (1996), but instead bring the trade-off to a dynamic world.

Related to my model's implication on renegotiation frequency, several recent papers study the impact of creditor structure and rollover risk on equilibrium debt maturity. Cheng and Milbradt (2012) solve for the optimal debt maturity given the trade-off between risk-shifting incentives and rollover failures. Huang, Oehmke and Zhong (2019) study the optimal number, size, and timing of repayments when the debtor cannot commit to repay and early termination is more costly. Brunnermeier and Oehmke (2013) show that excessive short-term debt may prevail in equilibrium with multiple creditors, despite the increased rollover risks.

Petersen and Rajan (1995) propose a model that illustrates how exogenous variation in lenders' market power affects the quality of the financed firms and hence their cost of credit. In contrast, I endogenize the variation in bargaining power by modeling the game between the firm and its creditors. For further research on the number of creditors, Ongena and Smith (2000a) provide a comprehensive survey.

Previous literature also examines the effects of debt renegotiation and rollover from an asset-pricing perspective. Mella-Barral and Perraudin (1997) and Mella-Barral (1999) study debt pricing when firms can renegotiate and 
service the troubled debt rather than defaulting right away, as in Leland (1994). He and Xiong (2012b) show that rollover losses as a result of illiquidity in the debt market can exacerbate a firm's credit risk. Hege and Mella-Barral (2005) examine an economy in which a firm can exchange liquidation rights for coupon concessions on debt. They study how this feature affects the credit risk premia as the number of creditors changes. With the creditor structure exogenously fixed, these authors focus on pricing the debt claims given the possibility of renegotiation or rollover frictions. In contrast, I focus on the optimal choice of creditor dispersion.

The rest of the paper is organized as follows. Section I details the dynamic debt rollover game and Section II characterizes creditor dispersion in equilibrium. Section III analyzes the evolution and comparative dynamics of creditor dispersion and relates these findings to empirical literature. Section IV shows how exogenous creditor structure and renegotiation frequency affect the debt rollover outcome. Section V extends the model by allowing the firm to keep cash and shows how cash holdings interact with creditor structure. Finally, Section VI concludes.

\section{Model Setup}

In Sections I.A and I.B, I introduce the baseline model, which features endogenous creditor dispersion in a dynamic debt rollover framework. I then discuss key modeling assumptions in Section I.C.

\section{A. The Project}

Time $t$ is discrete and the discount rate is $r>0$. At time $t=0$, a risk-neutral firm with no cash starts a long-term project that needs an upfront investment $I_{0}$. The project generates no interim cash flow but rather an observable liquidating dividend $Y_{t}$ at a random project maturity, denoted by $\tau_{\pi} \cdot{ }^{3}$ At the beginning of each period $t$, the project matures with probability $\pi$, generating final dividend $Y_{t}$. If the project does not mature, then a new fundamental $Y_{t+1}=Y_{t} z_{t+1}$ is realized. While all results are robust to considering more general stochastic processes, for simplicity I assume that the fundamental $Y_{t}$ remains at $Y_{0}$ until a good shock arrives, after which $Y_{t}$ deterministically grows at a rate of $\mu>r$. The good shock arrives with probability $p$ in each period. Formally, the periodic shock $z_{t+1} \in\{1,1+\mu\}$ follows a Markov chain with initial state $z_{1}=1$ and transition probabilities given by

$$
\left\{\begin{array}{l}
\operatorname{Prob}\left(z_{t+1}=1+\mu \mid z_{t}=1+\mu\right)=1 \\
\operatorname{Prob}\left(z_{t+1}=1+\mu \mid z_{t}=1\right)=p .
\end{array}\right.
$$

With a slight abuse of notation, when $z_{t}$ appears in superscripts, I denote by $G(o o d)$ and $B(a d)$ the states $z_{t}=1+\mu$ and $z_{t}=1$, respectively. At the end of

\footnotetext{
${ }^{3}$ I assume no interim cash flow for simplicity to focus on the key feature of debt rollover.
} 


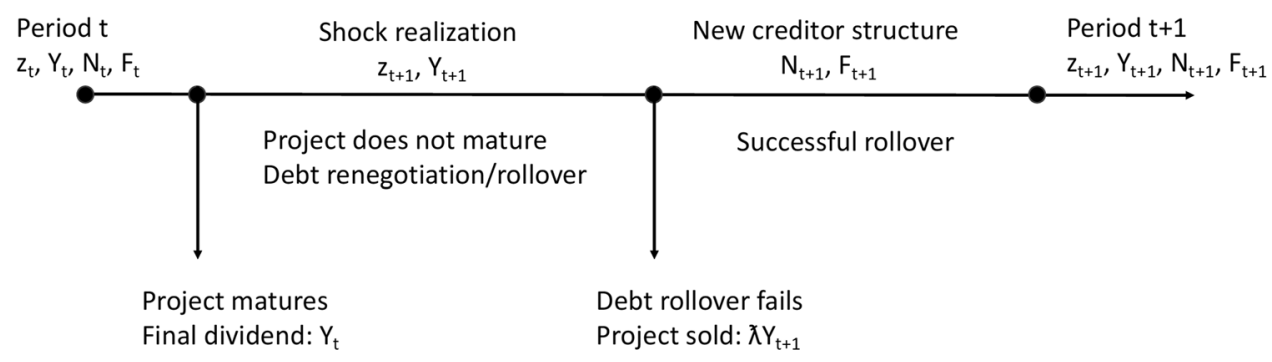

Figure 1. Timeline. The sequence of actions and the evolution of the state variables.

period $t-1$ (after the realization of $z_{t}$ ), the expected value of the final dividend can be calculated according to

$$
\left\{\begin{array}{l}
V_{F B}^{G}\left(Y_{t}\right) \equiv E\left(\frac{Y_{\tau_{\pi}}}{(1+r)^{\tau_{\pi}+1-t}} \mid Y_{t}, z_{t}=1+\mu\right)=\frac{\pi}{1+r-(1-\pi)(1+\mu)} Y_{t} \\
V_{F B}^{B}\left(Y_{t}\right) \equiv E\left(\frac{Y_{\tau_{\pi}}}{(1+r)^{\tau_{\pi}+1-t}} \mid Y_{t}, z_{t}=1\right)=\frac{\pi+(1-\pi) p(1+\mu) \frac{\pi}{1+r-(1-\pi)(1+\mu)}}{1+r-(1-\pi)(1-p)} Y_{t} .
\end{array}\right.
$$

The detailed mathematical derivation for (1) is in Appendix A. Denote by $v_{F B}^{z_{t}} Y_{t}\left(z_{t}=G\right.$ or $\left.B\right)$ the linear first-best firm values in (1). Throughout the paper I assume that $1+r>(1-\pi)(1+\mu)$, so $v_{F B}^{G}>v_{F B}^{B}$ are both finite. If the project does not mature in period $t$, it can be sold prematurely for $\lambda Y_{t+1}$. When $\lambda$ is sufficiently small, in particular, smaller than the expected value of the project in a bad state,

$$
\lambda<v_{F B}^{B},
$$

selling the project prematurely is never optimal.

\section{B. Dynamic Debt Rollover Game}

To focus on debt rollover, I assume that the firm can only issue one-period debt to short-lived creditors. Since the project does not generate any interim cash flow, the firm must repeatedly issue new debt to finance repayments to the maturing creditors. Figure 1 presents the timeline of the debt rollover game in each period. The firm enters period $t$ with shock $z_{t}$, fundamental $Y_{t}$, total face value of maturing debt contracts $F_{t}$, and $N_{t} \geq 1$ incumbent creditors. For simplicity, I assume that each creditor holds an equal amount of face value $\frac{F_{t}}{N_{t}}$. As discussed in Section I.C, introducing asymmetric debt holdings among creditors does not materially change the analysis.

In period $t$, the project first matures with probability $\pi$, generating final dividend $Y_{t}$. The incumbent creditors split the final dividend equally up to 
the promised face value, each receiving $\frac{1}{N_{t}} \min \left(F_{t}, Y_{t}\right) .{ }^{4}$ The equity receives the residual $\max \left(Y_{t}-F_{t}, 0\right)$. If the project does not mature, then the next period's fundamental $Y_{t+1}$ (or equivalently, the shock $z_{t+1}$ ) is realized and is publicly observed. One of the main frictions in this model is that the firm cannot commit to repaying its creditors, but instead always attempts to renegotiate its debt. Specifically, the firm meets each creditor sequentially and makes takeit-or-leave-it offer $S_{t}^{i}$ to the $i^{\text {th }}$ negotiating creditor, who is also the $i^{\text {th }}$ lender providing the loan in the previous period, $t-1$. The offer history is public information.

If the $i^{\text {th }}$ creditor is the first to decline the offer, I assume that the firm can avoid immediate default by selling the project for $\lambda Y_{t+1}$ in order to honor the repayment of $\frac{F_{t}}{N_{t}}$. Selling the project can be broadly interpreted in practice as downsizing investments, spinning off assets, or conducting fire sales. Since the company has not yet defaulted, automatic stay or equal treatment among creditors does not apply. Hence, creditor $i$ receives a payoff of $\min \left(\frac{F_{t}}{N_{t}}, \lambda Y_{t+1}\right)$. To simplify strategic actions, I assume that all subsequent creditors automatically refuse any renegotiation and demand the full face value $\frac{F_{t}}{N_{t}}$, which is paid from the total proceeds $\lambda Y_{t+1}$ sequentially until depletion. In addition, creditors $j<i$ that have already accepted the firm's offers are now at the rear of the collection queue. Therefore, creditors' payoff in the event of a renegotiation failure features "sequential service," as commonly assumed in the large literature following Diamond and Dybvig (1983). ${ }^{5}$ Mathematically, if the $i^{\text {th }}$ creditor declines the offer, the $i+k^{\text {th }}\left(k=0,1, \ldots, N_{t}-1\right)$ creditor receives repayment

$$
X_{t}^{i+k}= \begin{cases}\frac{F_{t}}{N_{t}} & \text { if }(k+1) \frac{F_{t}}{N_{t}} \leq \lambda Y_{t+1} \\ \lambda Y_{t+1}-k \frac{F_{t}}{N_{t}} & \text { if } k \frac{F_{t}}{N_{t}} \leq \lambda Y_{t+1}<(k+1) \frac{F_{t}}{N_{t}} \\ 0 & \text { if } \lambda Y_{t+1}<k \frac{F_{t}}{N_{t}},\end{cases}
$$

with the remaining $\max \left(\lambda Y_{t+1}-F_{t}, 0\right)$ going to the firm. Here, I use the convention that if $i+k>N_{t}$, it denotes the $i+k-N_{t}^{\text {th }}$ creditor. The first case in (3) captures full repayment to a creditor when the resale proceeds $\lambda Y_{t+1}$ are sufficient to honor this repayment. The second case characterizes the payoff to the last creditor who exhausts the (remaining) proceeds, with everyone to follow receiving zero as in the final case.

\footnotetext{
${ }^{4}$ One can alternatively assume arbitrary priority structure among the $N_{t}$ creditors when the project matures. The relevant quantity is the total payoff to creditors, $\min \left(F_{t}, Y_{t}\right)$.

${ }^{5}$ Alternatively, I can endow subsequent creditors with strategic actions to accept or decline their renegotiation offers. In addition, instead of sequential priority, one can assume that the nonnegotiating creditors $(j \neq i)$ have equal priority with respect to the remaining proceeds. The equilibrium outcome is robust to these modifications. As will soon be clear, the exact same coordination problem emerges as long as there is an advantage to being the first creditor to reject the offer.
} 
Since the first rejecting creditor receives $\min \left(\frac{F_{t}}{N_{t}}, \lambda Y_{t+1}\right)$, and the firm has all of the bargaining power, the renegotiated repayment must be

$$
S_{t}^{i}=\min \left(\frac{F_{t}}{N_{t}}, \lambda Y_{t+1}\right)
$$

Put differently, the firm offers its creditors their outside option: either the promised face value $\frac{F_{t}}{N_{t}}$ in full or the resale value $\lambda Y_{t+1}$. If all offers are accepted, then debt renegotiation is successful and the total renegotiated repayment

$$
\sum_{i=1}^{N_{t}} S_{t}^{i}=\min \left(F_{t}, N_{t} \lambda Y_{t+1}\right)
$$

must be refinanced into the next period.

The newly issued debt contracts maturing in period $t+1$ are sequentially offered to $N_{t+1}$ new creditors each with face value $\frac{F_{t+1}}{N_{t+1}}$. The $j^{\text {th }}$ creditor $\left(j \leq N_{t+1}\right)$ to receive the debt contract will also be the $j^{\text {th }}$ creditor to mature and negotiate in period $t+1$. This arrangement can be interpreted as staggered maturity structure within a period. In exchange, the $j^{\text {th }}$ creditor lends the firm $D_{t+1}^{z_{t+1}, j}$, which is the competitive price of this debt contract, taking into consideration possible premature termination and renegotiation in the future. Mathematically,

$$
\begin{aligned}
D_{t}^{z_{t}, j}\left(N_{t}, F_{t}, Y_{t}\right)= & \frac{1}{1+r}\{\underbrace{\pi \frac{1}{N_{t}} \min \left(F_{t}, Y_{t}\right)}_{\text {project matures }} \\
& \left.+(1-\pi) E_{t}[\underbrace{\mathbf{1}_{R O} S_{t}^{j}}_{\text {successful rollover }}+\underbrace{\left(1-\mathbf{1}_{R O}\right) X_{t}^{j}}_{\text {rollover failure }}]\right\},
\end{aligned}
$$

where $\mathbf{1}_{R O}$ is the indicator function that debt roll over is successful in period $t$. The value of an individual debt contract in (6) (maturing in period $t$ instead of $t+1$ for notational convenience) has three components: a repayment of $\frac{1}{N_{t}} \min \left(F_{t}, Y_{t}\right)$ when the project matures with probability $\pi$, a renegotiated repayment of $S_{t}^{j}$ if debt rollover is successful, and a termination repayment $X_{t}^{j}$, given by (3), should rollover fail. Using condition (5) and the fact that $\sum_{j=1}^{N_{t}} X_{t}^{j}=\min \left(F_{t}, \lambda Y_{t+1}\right)$ from (3), I aggregate (6) over all $N_{t}$ creditors and the 
total market value of debt is

$$
\begin{aligned}
& D_{t}^{z_{t}}\left(N_{t}, F_{t}, Y_{t}\right)=\sum_{j=1}^{N_{t}} D_{t}^{z_{t}, j}\left(N_{t}, F_{t}, Y_{t}\right)=\frac{1}{1+r}\{\underbrace{\pi \min \left(F_{t}, Y_{t}\right)}_{\text {project matures }} \\
& \left.+(1-\pi) E_{t}[\underbrace{\mathbf{1}_{R O} \min \left(F_{t}, N_{t} \lambda Y_{t+1}\right)}_{\text {successful rollover }}+\underbrace{\left(1-\mathbf{1}_{R O}\right) \min \left(F_{t}, \lambda Y_{t+1}\right)}_{\text {rollover failure }}]\right\} .
\end{aligned}
$$

The firm chooses the optimal creditor structure $\left(N_{t+1}^{*}, F_{t+1}^{*}\right)$ to maximize total firm value, which can be recursively expressed as

$$
\begin{aligned}
& V^{z_{t}}\left(N_{t}, F_{t}, Y_{t}\right)=\frac{1}{1+r}\{\underbrace{\pi Y_{t}}_{\text {project matures }} \\
& +(1-\pi) E_{t}[\underbrace{\mathbf{1}_{R O} \max _{N_{t+1}, F_{t+1}} V^{z_{t+1}}\left(N_{t+1}, F_{t+1}, Y_{t+1}\right)}_{\text {successful rollover }}+\underbrace{\left(1-\mathbf{1}_{R O}\right) \lambda Y_{t+1}}_{\text {rollover failure }}]
\end{aligned}
$$

subject to rolling over the renegotiated payments in (5),

$$
D_{t+1}^{z_{t+1}}\left(N_{t+1}, F_{t+1}, Y_{t+1}\right)=\underbrace{\min \left(F_{t}, N_{t} \lambda Y_{t+1}\right)}_{\text {renegotiated payments }} .
$$

For simplicity, I assume that the firm refinances the exact amount of repayment: the market value of all newly issued debt $D_{t+1}^{z_{t+1}}$ exactly equals the total renegotiated repayment as in equation (9). ${ }^{6}$ The upfront investment is financed by debt issuance in period 0 to $N_{1}$ creditors and total face value $F_{1}$, such that $D_{1}=I_{0}$. Expression (8) is intuitive. The project matures with probability $\pi$ generating final dividend $Y_{t}$. When the project does not mature, debt rollover is successful if the firm can find a creditor structure $\left(N_{t+1}, F_{t+1}\right)$ to raise the renegotiated payment of $D_{t+1}=\min \left(F_{t}, N_{t} \lambda Y_{t+1}\right)$. In this case, the firm optimizes over all feasible creditor structures such that $D_{t+1}$ can be raised and receives the continuation value $V^{z_{t+1}}$ from the next period; otherwise the project is sold prematurely for $\lambda Y_{t+1}$. Note that at the refinancing stage of period $t$, the total value of debt $D_{t+1}$ is fixed and given by (9), and therefore maximizing firm value $\left(V_{t+1}\right)$ is equivalent to equity value $\left(V_{t+1}-D_{t+1}\right)$ maximization.

Finally, when the firm is indifferent between several refinancing strategies, I assume that it prefers fewer creditors $\left(N_{t}\right)$ first and then a lower face value $\left(F_{t}\right)$ of debt. This assumption can be microfounded by adding an arbitrarily small cost to maintain each creditor relationship and to renegotiate down the

\footnotetext{
${ }^{6}$ In Section V, I show that in this baseline setup, the firm never borrows more money than necessary to refinance the maturing debt and keeps the excess cash inside the firm. Put differently, condition (9) can be established as a result rather than an assumption.
} 
maturing debt. When solving the model, I relax the integer restriction on the number of creditors $N_{t} \geq 1$.

\section{Remarks on the Modeling Assumptions}

\section{C.1. Creditors' Payoff in Renegotiation}

The payoff structure in the renegotiation game warrants further discussion. Similar to the sequential-service condition in Diamond and Dybvig (1983), the payoff function (3) gives priority to creditors whose debt matures sooner. By declining their renegotiation offers, these creditors can secure (partial) repayment at the cost of other creditors, thereby creating a coordination problem that is at the heart of the model. The main predictions of the model continue to hold as long as there is a coordination problem (even for reasons unrelated to the split of repayment) that is more severe with more creditors. Such coordination problems are widely documented empirically and can emerge theoretically as an outcome of an efficient mechanism design. ${ }^{7}$

One feature that could alleviate the coordination problem in practice is the legal arrangement known as "avoidable preference," which allows creditors to claw back unusual payments made to other "preferred" creditors within the 90 days prior to default. However, the legal actions required to enforce this rule are expensive. In addition, creditors are arguably not deterred from accepting "preference" because scrambling to demand repayment is still a dominant strategy. As Countryman (1985) points out, "[I]t seems ridiculous to expect deterrence [of creditors to accept preferred payments]. [F]irst, a preferred creditor can retain his preference if the 90 day period elapses before bankruptcy... Second, ... preferred creditors can escape all consequences... by simply surrendering his preference."

Perhaps most seriously, the avoidable preference rule can create an incentive for creditors to run. Knowing that payments seized 90 days prior to bankruptcy can be safely retained, creditors in a distressed firm have an incentive to demand payment (in the model, refuse to accept renegotiation offers) as early as possible to stay out of the 90 -day window. ${ }^{8}$ Indeed, this concern is a major reason why law experts question the effectiveness of such a policy. For example, McCoid (1981) argues that "a creditor frequently will ... accept the preference and hope for a success [to retain the payment]... Moreover, ... there is a companion incentive to act as early as possible and increase the odds of effecting the transfer out of the 90-day period."

\footnotetext{
${ }^{7}$ Using a natural experiment, Hertzberg, Liberti, and Paravisini (2011) show that creditors reduce lending when they anticipate that other incumbent creditors will learn negative information about the firm. Gilson, John, and Lang (1990) and Brunner and Krahnen (2008) show that creditor dispersion adversely affects the probability of a successful workout for distressed firms. From a theoretical perspective, Calomiris and Kahn (1991), Berglöf and Von Thadden (1994), Bolton and Scharfstein (1996), Diamond (2004), and Zetlin-Jones (2014) show that coordination failure can naturally stem from optimal financing contracts.

${ }^{8}$ See Zhong and Zhou (2020) for a quantitative analysis of this effect.
} 
In summary, the simple payoff structure (3) captures the essence of coordination problems that arise with multiple creditors.

\section{C.2. Uneven Distribution of Face Value among Creditors}

Throughout the paper, I assume that the firm must issue debt with identical face value to all creditors. However, the model's intuition does not depend crucially on this assumption. In fact, one can show that a creditor structure with more asymmetrically distributed face values is similar to having fewer creditors.

Consider two creditors with face values $F^{1} \leq F^{2}$. To make renegotiation offers acceptable to both creditors, the firm must repay a total of

$$
\min \left(F^{1}, \lambda Y\right)+\min \left(F^{2}, \lambda Y\right)
$$

Given a total face value $F$ shared between two creditors, identical face values (i.e., $F^{1}=F^{2}=\frac{F}{2}$ ) attain the maximum renegotiated repayment in (10): $2 \min \left(\frac{F}{2}, \lambda Y\right)$. This is the case I focus on throughout the paper. The smaller the $F^{1}$, the smaller the total repayment. In the extreme case in which $F^{1}=0$, the repayment in (10) reduces to $\min (F, \lambda Y)$, the same as the case with a single creditor. Intuitively, renegotiation with a smaller creditor is more difficult, whereas forcing concession from a larger one is easier. In the limit, if a large creditor holds almost all of the outstanding debt, the outcome approaches the single-creditor case.

\section{Model Solution}

I start by introducing the key quantity—debt capacity-in Section II.A. In Section II.B, I describe the firm's refinancing strategy $\left(N_{t+1}^{*}, F_{t+1}^{*}\right)$, which also governs the evolution of creditor dispersion. The key trade-off associated with more creditors is the benefit of stronger commitment power for the firm to repay its debt against the cost of higher rollover risk. In equilibrium, the firm chooses the number of creditors to simultaneously maintain sufficient commitment power and reduce rollover risk.

\section{A. Debt Capacity}

Debt capacity is the maximum level of debt that a firm can borrow by choosing some face value $F_{t+1}$ and number of creditors $N_{t+1}$. Formally, I define debt capacity $D C_{t+1}=D C^{z_{t+1}}\left(Y_{t+1}\right)$ as

$$
D C^{z_{t+1}}\left(Y_{t+1}\right) \equiv \max _{N_{t+1}, F_{t+1}} D^{z_{t+1}}\left(N_{t+1}, F_{t+1}, Y_{t+1}\right)
$$


For a company to roll over its debt successfully (i.e., $\mathbf{1}_{R O}=1$ in (6)), the total renegotiated repayment in (5) must be bounded by the debt capacity,

$$
\min \left(F_{t}, N_{t} \lambda Y_{t+1}\right) \leq D C^{z_{t+1}}\left(Y_{t+1}\right) .
$$

Using the rollover condition (12), I can rewrite debt capacity $D C_{t}=D C^{z_{t}}\left(Y_{t}\right)$ from (7) and (11) as the invariant function to the problem

$$
\begin{aligned}
& D C^{z_{t}}\left(Y_{t}\right) \equiv \max _{N_{t}, F_{t}} D^{z_{t}}\left(N_{t}, F_{t}, Y_{t}\right) \\
& =\frac{1}{1+r}\{\underbrace{\pi \min \left(F_{t}, Y_{t}\right)}_{\text {project matures }}
\end{aligned}
$$

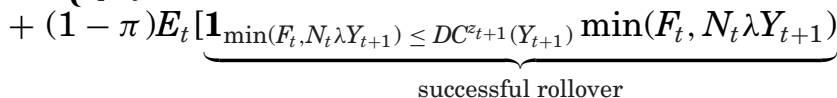

$$
\begin{aligned}
& +\underbrace{\left.\mathbf{1}_{\min \left(F_{t}, N_{t} \lambda Y_{t+1}\right)>D C^{z_{t+1}\left(Y_{t+1}\right)} \min \left(F_{t}, \lambda Y_{t+1}\right)}\right)}_{\text {rollover failure }}\} .
\end{aligned}
$$

The trade-off associated with more creditors $N_{t}$ becomes apparent in (13). On the one hand, having more creditors improves the firm's commitment power, that is, the total (renegotiated) repayment- $\min \left(F_{t}, N_{t} \lambda Y_{t+1}\right)$-weakly increases. Recall from (4) that when renegotiation results in a reduction of the original face value (i.e., when $\frac{F_{t}}{N_{t}}>\lambda Y_{t+1}$ ), the firm must pay back the resale value $\lambda Y_{t+1}$ to each creditor. Having more creditors therefore commits the firm to repay a higher multiple of the resale value in the event of a renegotiation-a total repayment of $N_{t} \lambda Y_{t+1}$ to all creditors. Instead of renegotiating, the firm can repay the debt in full (i.e., when $\frac{F_{t}}{N_{t}} \leq \lambda Y_{t+1}$ ), which is also more likely to occur with more creditors $\left(N_{t}\right)$. On the other hand, a dispersed creditor structure risks inefficient termination because a higher renegotiated repayment $\min \left(F_{t}, N_{t} \lambda Y_{t+1}\right)$ is less likely to be refinanced (the rollover condition (12) fails more often). This higher chance of inefficient termination reduces the ex ante value of debt.

I now introduce a technical assumption purely for expositional purposes:

$$
\lambda>\frac{1}{1+r}\{\pi+(1-\pi)[(1+\mu) p+1-p] \lambda\} .
$$

The essence of assumption (14) is to rule out having a single creditor $N_{t}=$ 1 as an absorbing state, which means that the maximum repayment offered to a single creditor $\lambda Y_{t}$ can be refinanced with a single creditor again in the next period. ${ }^{9}$ A violation of (14) creates a region of creditor dispersion (when $N \geq 1$ is sufficiently low) such that firm value is always first-best, in which

\footnotetext{
${ }^{9}$ The right-hand side of (14) is the borrowing capacity from a single creditor $\left(N_{t}=1\right)$ in a bad state $\left(z_{t}=1\right)$, which is attained for any face value $F_{t} \geq(1+\mu) Y_{t}$. If the project matures, $\min \left(F_{t}, Y_{t}\right)=Y_{t}$ is paid to the creditor. If the project does not mature, since $N_{t}=1$, the
} 
case the firm's choice of creditor dispersion becomes irrelevant. The following proposition analytically characterizes the debt capacity that is linear in $Y_{t}$.

Proposition 1. (Characterization of debt capacity): The debt capacity in the good state $D C^{G}\left(Y_{t}\right) \equiv \kappa^{G} Y_{t}$ is the first-best value of the project:

$$
\kappa^{G}=v_{F B}^{G}=\frac{\pi}{1+r-(1-\pi)(1+\mu)} .
$$

The debt capacity in the bad state $D C^{B}\left(Y_{t}\right) \equiv \kappa^{B} Y_{t}$ is given by

$$
\kappa^{B}=\frac{1}{1+r}\{\underbrace{\pi}_{\text {project matures }}+(1-\pi)[\underbrace{p v_{F B}^{G}(1+\mu)}_{\text {successful rollover }}+\underbrace{(1-p) \lambda}_{\text {rollover failure }}]\} .
$$

As a mild additional assumption to (2), I further restrict $\lambda$ to be small enough such that $\kappa^{B}>\lambda$. This assumption simply states that the resale value can be refinanced in the bad state. Should this condition fail, no renegotiation is feasible in the bad state, rendering the dynamics uninteresting.

Proposition 1 is intuitive. In the good state, fundamental $Y_{t}$ deterministically grows at a rate of $\mu$ every period. The entire firm value can be pledged to creditors by choosing a sufficiently dispersed creditor structure- $-N_{t}=\frac{v_{F B}^{G}}{\lambda}$ and $F_{t}=\max \left(Y_{t}, v_{F B}^{G}(1+\mu) Y_{t}\right)$. If the project matures, creditors receive the entire final dividend $\min \left(F_{t}, Y_{t}\right)=Y_{t}$, otherwise they receive the entire continuation value of the firm even after renegotiation $\min \left(F_{t}, N_{t} \lambda Y_{t+1}\right)=v_{F B}^{G}(1+\mu) Y_{t}$.

In the bad state, the firm can potentially borrow the maximum amount in two ways, reflecting the aforementioned trade-off between the benefit of commitment power and the cost of rollover risk. First, the firm can choose a large pool of creditors $N_{t}=\frac{\kappa^{G}}{\lambda}$ and promise a high repayment $F_{t}=\max \left(Y_{t}, \kappa^{G}(1+\right.$ $\mu) Y_{t}$ ) to pledge the entire firm value from the good state (i.e., when $z_{t+1}=$ $1+\mu)$. However, this high commitment power is a double-edged sword. If the state remains bad (i.e., $z_{t+1}=1$ ), the firm is unable to write off a sufficient amount of the maturing debt and thereby suffers rollover failure, because the renegotiated repayment $\left(\min \left(F_{t}, \lambda N_{t} Y_{t}\right)=\kappa^{G} Y_{t}\right)$ is greater than the debt capacity $\kappa^{B} Y_{t}$. In this case, creditors receive a total payoff of $\lambda Y_{t}$. Taken together, expression (16) gives the ex ante value of debt with this dispersed creditor structure.

Alternatively, the firm could borrow from a smaller pool of creditors $N_{t}=\frac{\kappa^{B}}{\lambda}$ and set a lower face value $F_{t}=\max \left(Y_{t}, \kappa^{B}(1+\mu) Y_{t}\right)$. With fewer creditors, debt renegotiation becomes easier: in the bad state, the total renegotiated repayment of $\lambda N_{t} Y_{t}=\kappa^{B} Y_{t}$ can still be refinanced. The firm can therefore completely avoid the inefficient rollover failure. However, easier renegotiation means that

repayment is $\min \left(F_{t}, \lambda Y_{t+1}\right)=\lambda Y_{t+1}$ regardless of whether debt rollover is successful. Therefore, the maximum pledgeable income with a single creditor (similar to (13)) is $\frac{1}{1+r}\left\{\pi Y_{t}+(1-\pi)[p \lambda(1+\right.$ $\left.\left.\mu) Y_{t}+(1-p) \lambda Y_{t}\right]\right\}$. 
the firm cannot commit to pay the full value of the project in the good state back to the creditors, reducing pledgeable income. Mathematically, with $N_{t}=\frac{\kappa^{B}}{\lambda}$ creditors, the maximum repayment in the good state is $\kappa^{B}(1+\mu) Y_{t}$, which is strictly less than the debt capacity $\kappa^{G}(1+\mu) Y_{t}$. In this case, the ex ante value of debt is

$$
\kappa^{\dagger B} Y_{t} \equiv \frac{1}{1+r}\left\{\pi+(1-\pi)[p(1+\mu)+1-p] \kappa^{B}\right\} Y_{t}
$$

Comparing (17) with (16), one can clearly see that by choosing a more concentrated creditor structure, the firm sacrifices commitment power in the good state (i.e., $(1+\mu) Y_{t} \kappa^{B}$ versus $\left.(1+\mu) Y_{t} \kappa^{G}\right)$ for the more efficient outcome in the bad state (i.e., $\kappa^{B} Y_{t}$ versus $\lambda Y_{t}$ ). The proof of Proposition 1 in Appendix A shows that $\kappa^{B}$ given by (16) always dominates $\kappa^{\dagger B}$ in (17).

Similar to (11), it will be useful to define debt capacity with at most $N$ creditors as the maximum level of debt that can be raised from at most $N$ creditors

$$
D C_{N}^{z} \equiv \max _{F, N^{\prime} \leq N} D^{z}\left(N^{\prime}, F, Y\right) \equiv \kappa_{N}^{z} Y,
$$

where the second identity uses the fact that the value of debt $D^{z}(N, F, Y)$ is homogeneous of degree one in $(F, Y)$. The following corollary of Proposition 1 characterizes $\kappa_{N}^{z}$.

CoROllary 1: In the good state, the debt capacity with at most $N$ creditors is given by

$$
\kappa_{N}^{G}=\frac{1}{1+r}\left[\pi+(1-\pi)(1+\mu) \lambda \min \left(N, \frac{v_{F B}^{G}}{\lambda}\right)\right] .
$$

In the bad state, the debt capacity with at most $N$ creditors is given by

$$
\kappa_{N}^{B}= \begin{cases}\frac{1}{1+r}\{\pi+(1-\pi)[p(1+\mu)+1-p] \lambda N\} & \text { if } N \leq \frac{\kappa^{B}}{\lambda} \\ \max \left(\frac{\pi+(1-\pi)[p(1+\mu) N+1-p] \lambda}{1+r}, \kappa^{\dagger B}\right) & \text { if } \frac{\kappa^{B}}{\lambda}<N<\frac{\kappa^{G}}{\lambda} \\ \kappa^{B} & \text { if } \frac{\kappa^{G}}{\lambda} \leq N .\end{cases}
$$

In the good state, the firm can set a face value $F_{t}=\max \left(Y_{t}, \min \left(N \lambda, v_{F B}^{G}\right)(1+\right.$ $\left.\mu) Y_{t}\right)$. When the project matures, this face value allows the firm to pledge the entire final dividend $(1+\mu) Y_{t}$. Otherwise, the firm repays the maximum amount that can be enforced by $N$ creditors $N \lambda(1+\mu) Y_{t}$, up to the first-best firm value $v_{F B}^{G}(1+\mu) Y_{t}$. In the first case of the bad state where $N \leq \frac{\kappa^{B}}{\lambda}$, the firm always survives renegotiation and the face value of $\max \left(Y_{t}, N \lambda(1+\mu) Y_{t}\right)$ maximizes the value of debt. In the second case where the maximum $N \in$ $\left(\frac{\kappa^{B}}{\lambda}, \frac{\kappa^{G}}{\lambda}\right)$, there are two possibilities similar to the aforementioned trade-off between (16) and (17). The firm can choose to pledge the maximum enforceable repayment with $N$ creditors from the good state by setting face value $F_{t}=\max \left(Y_{t}, N \lambda(1+\mu) Y_{t}\right)$, and risk termination in the subsequent bad state. 
Alternatively, the firm can choose to limit the number of creditors to $\frac{\kappa^{B}}{\lambda}$ and thereby ensure successful debt rollover in both states. The maximum value of debt in this alternative is given by $\kappa^{\dagger B} Y_{t}$ in (17). In the final case, when creditor dispersion can be large enough, the entire debt capacity can be achieved.

I end this subsection with a brief discussion of the possibility of multiple equilibria. As is common in many dynamic games, in general the equilibrium is not unique. In this model, multiplicity can emerge from two potential sources. First, there might be equilibria with time-dependent strategies. I rule out these strategies by focusing on Markov perfect equilibria. Second, debt capacities $D C^{z}(Y)$ have a self-fulfilling feature. Specifically, the fixed-point problem in (13) that determines debt capacities may have multiple solutions. Low debt capacity tomorrow reduces the odds of a successful debt rollover, resulting in low debt capacity today, and vice versa. Despite this theoretical possibility, the stochastic process specified in Section I guarantees the unique solution characterized by Proposition 1.

\section{B. The Dynamic of Creditor Dispersion}

We are now ready to characterize the key equilibrium variables of interest, namely, the firm's refinancing strategy $\left(N_{t+1}^{*}, F_{t+1}^{*}\right)$, which also governs the evolution of creditor dispersion. I start by exploring the model's linearity in $Y_{t}$ and reduce the exogenous state variables to $z_{t}$. Next, I collapse the two endogenous state variables $\left(N_{t}, F_{t}\right)$ into a single one: firm's market leverage $d_{t}^{z}$, which is defined as

$$
d_{t}^{z_{t}}\left(N_{t}, f_{t}\right) \equiv \frac{D^{z_{t}}\left(N_{t}, F_{t}, Y_{t}\right)}{Y_{t}}
$$

where $f_{t}=\frac{F_{t}}{Y_{t}}$ is the normalized face value, or book leverage. Similarly, I normalize total firm value:

$$
v_{t}^{z_{t}}\left(N_{t}, f_{t}\right)=\frac{V^{z_{t}}\left(N_{t}, F_{t}, Y_{t}\right)}{Y_{t}}
$$

Following the normalization, the condition for successful debt rollover (i.e., $\left.\mathbf{1}_{R O}=1\right)$ in (12) can be simplified to

$$
\min \left(f_{t}, N_{t} \lambda z_{t+1}\right) \leq \kappa^{z_{t+1}} z_{t+1} .
$$

From (7) and (9), the firm's leverage satisfies

$$
\begin{aligned}
& d_{t}^{z_{t}}\left(N_{t}, f_{t}\right)=\frac{1}{1+r}\{\underbrace{\pi \min \left(f_{t}, 1\right)}_{\text {project matures }} \\
& \left.+(1-\pi) E_{t}[\underbrace{\mathbf{1}_{R O} d_{t+1}^{z_{t+1}} z_{t+1}}_{\text {successful rollover }}+\underbrace{\left(1-\mathbf{1}_{R O}\right) \min \left(f_{t}, \lambda z_{t+1}\right)}_{\text {rollover failure }}]\right\} .
\end{aligned}
$$


The firm's optimization problem in (8) and (9), which determines its refinancing strategy $\left(N_{t+1}^{*}, f_{t+1}^{*}\right)$, becomes

$$
\begin{aligned}
& v_{t}^{z_{t}}\left(d_{t}^{z_{t}}\right)=\frac{1}{1+r}\{\pi \\
& \left.+(1-\pi) E_{t}\left[\mathbf{1}_{R O} \max _{N_{t+1}, f_{t+1}} v_{t+1}^{z_{t+1}}\left(d_{t+1}^{z_{t+1}}\right) z_{t+1}+\left(1-\mathbf{1}_{R O}\right) \lambda z_{t+1}\right]\right\}
\end{aligned}
$$

such that the firm must refinance the renegotiated leverage

$$
d^{z_{t+1}}\left(N_{t+1}, f_{t+1}\right)=\min \left(\frac{f_{t}}{z_{t+1}}, N_{t} \lambda\right)
$$

The next proposition captures the essence of the firm's refinancing strategy. The analytical expressions for $\left(N_{t+1}^{*}\left(d_{t+1}^{z_{t+1}}\right), f_{t+1}^{*}\left(d_{t+1}^{z_{t+1}}\right)\right)$ as functions of the state variables $\left(z_{t+1}, d_{t+1}\right)$ are relegated to Appendix A.

PROPOSITION 2. (Refinancing strategy): The firm always chooses the most concentrated creditor structure such that the total (renegotiated) repayment $\min \left(F_{t}, N_{t} \lambda Y_{t+1}\right)$ can be refinanced. Mathematically, the optimal $N_{t+1}^{*}$ is the smallest $N$ such that

$$
\kappa_{N}^{z_{t+1}} \geq d_{t+1}^{z_{t+1}}
$$

The good state $\left(z_{t+1}=1+\mu\right)$ is tedious, because this state is absorbing and the problem becomes deterministic. The project is never prematurely terminated and firm value is therefore always first-best. As a result, the firm is indifferent with respect to creditor structure and by assumption will refinance from the least number of creditors $N_{t}$. At the end of this section, I discuss why this trivial outcome in the good state continues to hold under more general fundamental processes.

The more interesting case is when the fundamental is still bad, that is, $z_{t+1}=1$. The intuition is clear from the firm's optimization problem (8) and (9). The number of creditors is the mechanism through which the firm allocates realized repayments across future states. On the one hand, firms can choose a more dispersed creditor structure and therefore cannot easily renegotiate repayments regardless of the fundamental realization. This feature results in more equalized repayments across states. For instance, when $\lambda N_{t+1} Y_{t+1} \geq F_{t+1}$, it is impossible for the firm to renegotiate and the required repayment (i.e., the promised face value $\left.\min \left(F_{t+1}, \lambda N_{t+1} Y_{t+1} z_{t+2}\right)=F_{t+1}\right)$ is a constant independent of $z_{t+2}$. Equivalently, the associated leverage $d_{t+2}=\frac{F_{t+1}}{Y_{t+2}}$ is most heterogeneous across the two states, and higher when $z_{t+2}=1$. On the other hand, when the firm chooses a more concentrated creditor structure, renegotiation becomes easier, and the realized repayment is higher in the good state. For example, if $\lambda N_{t+1}(1+\mu) Y_{t+1} \leq F_{t+1}$, then the firm can renegotiate the repayment to $\lambda N_{t+1} Y_{t+2}$ in both states, which is higher if $z_{t+2}=1+\mu$. The required leverage $d_{t+2}=\frac{\lambda N_{t+1} Y_{t+2}}{Y_{t+2}}=\lambda N_{t+1}$ is identical in both states. 
In equilibrium, the firm finds it optimal to allocate as much repayment as possible to the good state, because the entire first-best firm value can be pledged to creditors without rollover risk (recall Proposition 1). The resulting lower repayment in the bad state (or equivalently lower leverage) improves the firm value since it facilitates subsequent debt rollover. Hence, the firm maximizes the repayment inequality across states by borrowing from as few creditors as possible. As a corollary of the firm's refinancing strategy in Proposition 2 , I next qualitatively characterize the evolution of creditor structure over time.

COROLlary 2: The number of creditors decreases in a good state and increases in a bad state. Mathematically, $N_{t+1}^{*} \leq N_{t}^{*}$ if $z_{t+1}=1+\mu$ and $N_{t+1}^{*} \geq N_{t}^{*}$ if $z_{t+1}=1$.

From Proposition 2, we know that the evolution of creditor dispersion $N_{t}$ is driven by the leverage process $d_{t}$ in equilibrium. In the good state, fundamental $Y_{t}$ grows deterministically by $1+\mu$ every period. The value of debt in (13) can be rewritten recursively as

$$
D_{t}^{G}=\frac{1}{1+r}\{\underbrace{\pi \min \left(F_{t}, Y_{t}\right)}_{\text {project matures }}+\underbrace{(1-\pi) D_{t+1}^{G}}_{\text {project does not mature }}\} \text {. }
$$

The proof in Appendix A shows that $D_{t}^{G}$ grows by less than $1+\mu$ per period. To gain intuition, consider the example of risk-free debt issuance $\left(D_{t}^{G} \leq\right.$ $\frac{1}{1+r} Y_{t}$ or equivalently $\left.d_{t}^{G} \leq \frac{1}{1+r}\right)$. In this case, the market value of $\operatorname{debt} D_{t+1}^{G}=$ $F_{t}=(1+r) D_{t}^{G}$ grows only by the discount rate $1+r<1+\mu$. The fundamental grows more rapidly than the value of debt, and therefore both leverage $d_{t+1}^{G}=\frac{(1+r) D_{t}}{(1+\mu) Y_{t}}=\frac{1+r}{1+\mu} d_{t}^{G}$ and the number of creditors $N_{t+1}$ decrease in the good state. ${ }^{10}$

In the bad state, the relevant case is that the firm survives even when the bad state persists in the next period. Conditional on survival, the value of debt can be recursively written as

$$
D_{t}^{B}=\frac{1}{1+r}\{\underbrace{\pi \min \left(F_{t}, Y_{t}\right)}_{\text {project matures }}+(1-\pi)[\underbrace{p D_{t+1}^{G}}_{\text {state switches to good }}+\underbrace{(1-p) D_{t+1}^{B}}_{\text {state stays bad }}]\} .
$$

Over time, the value of debt must increase, that is, $D_{t+1}^{B}>D_{t}^{B}$, to compensate for both the time discount $\frac{1}{1+r}$ and possible default upon project maturity if $F_{t}>$ $Y_{t}$. Since the fundamental $Y_{t}$ does not change in the bad state, both leverage $d_{t+1}$ and creditor dispersion $N_{t+1}$ increase.

\footnotetext{
${ }^{10}$ When the debt is not risk free, the value of debt $D_{t+1}$ needs to grow by more than $1+r$ to compensate for the default risk: project maturing leads to a repayment $Y_{t}$ strictly less than the promised face value $F_{t}$. The proof in Appendix A shows that even in this case, $D_{t+1}<(1+\mu) D_{t}$ and leverage still decreases.
} 


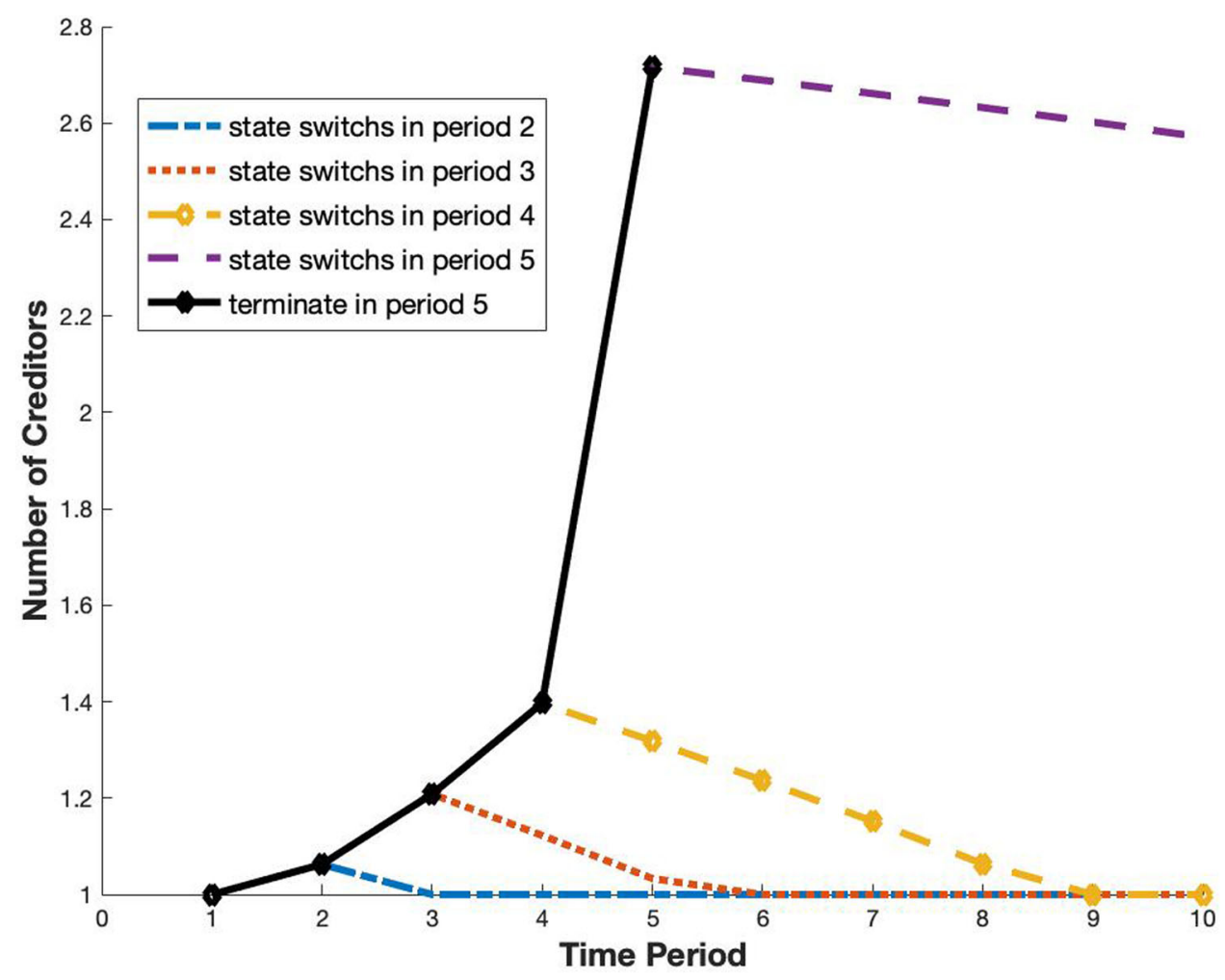

Figure 2. Typical sample paths. This figure plots a set of typical sample paths of creditor dispersion $N_{t}^{*}$ conditional on the fundamental state $z_{t}$ switching to good in periods $2,3,4,5$, and 6 . The number of creditors increases prior to the arrival of the good shock and decreases afterward. If the good shock arrives in or after period 6, the firm is terminated when the debt matures in period 5. (Color figure can be viewed at wileyonlinelibrary.com)

Figure 2 depicts the main features of Proposition 2 and Corollary 2. In the figure, I plot the evolution of creditor dispersion for a firm with the following parameters: state-switching probability $p=0.3$, maturing intensity $\pi=0.1$, resale value $\lambda=0.6$, discount rate $r=0.3$, growth rate $\mu=0.39$, and initial leverage $\frac{D_{1}}{Y_{1}}=0.95 * \frac{\lambda}{1+r}$. Different curves in the figure represent different sample paths of $N_{t}$ conditional on whether the good shock arrives in periods $2,3,4$, 5 , and 6 . I choose the initial leverage such that the first debt contract maturing in period 1 is risk free and the sample paths are most typical. The firm in this example starts in a bad state $\left(z_{t}=1\right)$. Since there is no growth in the bad state, the face value of debt $F_{t}$ and leverage $d_{t}$ increase gradually. To support this higher leverage, the firm must increase creditor dispersion $N_{t}$ and commit a larger fraction of its total value to its lenders. This effect is captured by the steadily increasing solid dark line in Figure 2. If the bad state persists for sufficiently long, the firm exhausts its debt capacity and faces termination. In this example, debt rollover fails in period 5 following a bad state realization $z_{6}=1$. 
Otherwise, if the state turns good $\left(z_{t}=1+\mu\right)$ at some point prior to period 6 , the fundamental $Y_{t}$ grows and leverage decreases. Consequently, the firm consolidates creditors gradually, captured by the dashed curves in the figure.

It is worth noting that the firm's ability to pledge its entire firm value in the good state relies on the specification that the good state $\left(z_{t}=1+\mu\right)$ is absorbing. This specification greatly simplifies the exposition of the model. In general, if a good state can also switch to a bad one, then a firm in a good state can still suffer subsequent rollover failures. Therefore, total firm value in the good state is no longer first-best and becomes dependent on the amount of leverage in this state. Hence, there is a trade-off between expected rollover risk in the good and bad states, and the firm may choose to limit repayment in the good state by having more creditors. Although an analytical solution is not generally available with the additional theoretical complication, numerical analysis suggests that the predictions in Proposition 2 and Corollary 2 are robust: firms increase creditor dispersion when the fundamental deteriorates and vice versa.

\section{Creditor Dynamics and Firm Characteristics}

In the time series, Proposition 2 and Corollary 2 show that creditor dispersion is negatively related to a firm's fundamental shocks $z_{t}$ : a firm increases creditor dispersion following bad shocks. In this section, I analyze the comparative dynamics of creditor dispersion with respect to the firm's growth rate $\mu$, or with a slight abuse of language, the "cross section" of creditor dispersion. In contrast to the time-series findings, a firm's average creditor dispersion over its lifetime can be positively correlated with the firm's quality: a high-growth firm can have more creditors on average. This result is developed in Section III.A. The sharp contrast between the time-series and cross-sectional analysis highlights the importance of using a dynamic model to analyze firms' creditor structure. These predictions also help reconcile the seemingly contradictory empirical findings and link them to classic theories on creditor dispersion, as discussed in Section III.B.

\section{A. Comparative Dynamics with Respect to Growth Rate}

Consider a firm with an exogenously higher growth rate $\mu$. Since this firm is of better quality, both its first-best value and debt capacity are higher. The same debt contract issued by this higher-growth firm is more valuable, due to the weakly higher (renegotiated) repayment in the good state (i.e., $\min \left(F_{t+1}, N_{t+1} \lambda(1+\mu) Y_{t+1}\right)$ from condition (5)). In addition, the higher debt capacity makes it less likely to suffer rollover failures. Consequently, this firm can choose a smaller number of creditors and still achieve the same leverage. The required leverage and creditor dispersion therefore increase (decrease) more slowly (rapidly) in a bad (good) state. The following result as a corollary to Propositions 1 and 2 summarizes these properties. 
Corollary 3: Consider two firms with different growth rates $\mu_{2}>\mu_{1}$.

1. The firm with a higher growth rate $\mu_{2}$ has higher borrowing capacity in both states: $\left.\kappa^{z}\right|_{\mu_{2}}>\left.\kappa^{z}\right|_{\mu_{1}}$ for $z=G, B$.

2. Suppose both firms need to refinance the same leverage $\left(d_{t+1}=\frac{D_{t+1}}{Y_{t+1}}\right)$ into period $t+1$. Then the higher-growth firm chooses fewer creditors: $\left.N_{t+1}^{*}\right|_{\mu_{1}} \geq$ $\left.N_{t+1}^{*}\right|_{\mu_{2}}$.

Statement 2 in Corollary 3 suggests that firms with higher asset growth increase creditor dispersion more slowly and therefore should have fewer creditors on average, similar to the time-series predictions in Corollary 2. (Recall that firms reduce creditor dispersion following good shocks.) However, this is only half of the story. With the dynamic aspect of creditor dispersion, this prediction may be reversed. Statement 1 in Corollary 3 suggests that firms with higher asset growth have higher borrowing capacity and can therefore support a larger amount of creditors without rollover failure. Specifically, the highgrowth $\mu_{2}$ firm can survive with $\frac{\left.\kappa^{B}\right|_{\mu_{1}}}{\lambda}<N \leq \frac{\left.\kappa^{B}\right|_{\mu_{2}}}{\lambda}$ creditors in the bad state, while the low-growth $\mu_{1}$ firm would have suffered a rollover failure. This channel implies that the time-series average number of creditors (defined in (23) below) could be higher for high-growth firms, even though it may take longer for these firms to expand the borrowing pool to any given size. ${ }^{11}$

I conclude this subsection with a numerical example that demonstrates the two opposing channels discussed above. The parameters in the example are $(p, \pi, \lambda, r)=(0.3,0.1,0.6,0.3)$, and I vary the growth rate $\mu$ between 0.32 and 0.44 . As $\mu$ changes, the first-best value of the project changes too. To ensure that all firms start equally indebted and that their creditor structure is equally dispersed, I set the initial leverage to $d_{1}=\frac{\pi+(1-\pi)[p(1+\mu)+1-p] \lambda}{1+r}$, which is the highest leverage with a single creditor, $N_{1}^{*}=1 .^{12}$ In this example, I focus on the bad state in which the number of creditors gradually increases. In Figure 3, I plot the dynamics of creditor dispersion $N_{t}^{*}$ for firms with $\mu=0.32$, $0.36,0.39$, and 0.41 conditional on the state staying bad. The trajectories for higher-growth firms are longer (as predicted by statement 1 in Corollary 3), and flatter on the common domain (as predicted by statement 2 in Corollary 3 ). The number of periods the firm can survive in a bad state ranges from $T=2$ (for $\mu=0.32$ ) to $T=16$ (for $\mu=0.44$ ), as plotted in the left panel of Figure 4 .

\footnotetext{
${ }^{11}$ In Appendix B, I present a static version of the model, which also predicts that the number of creditors in a high-growth firm increases less rapidly (statement 2 in Corollary 3). However, this static model cannot capture the dynamic intuition: a high-growth firm can survive longer due to its larger debt capacity (statement 1 in Corollary 3 ).

12 Note that the selected $d_{1}$ is the debt capacity with a single creditor on the right-hand side of (14). I do not choose lower initial leverage because even though the firm also has a single creditor in this case, the choice of leverage can be arbitrary and therefore lacks discipline. I can instead choose a higher $d_{1}$ such that $N_{1}^{*}>1$ is the same (there is indeed a one-to-one mapping between $d_{1}$ and $N_{1}^{*}$ in this case). The qualitative result is exactly the same. Therefore, the maximum leverage with $N_{1}^{*}=1$ is a natural starting point.
} 


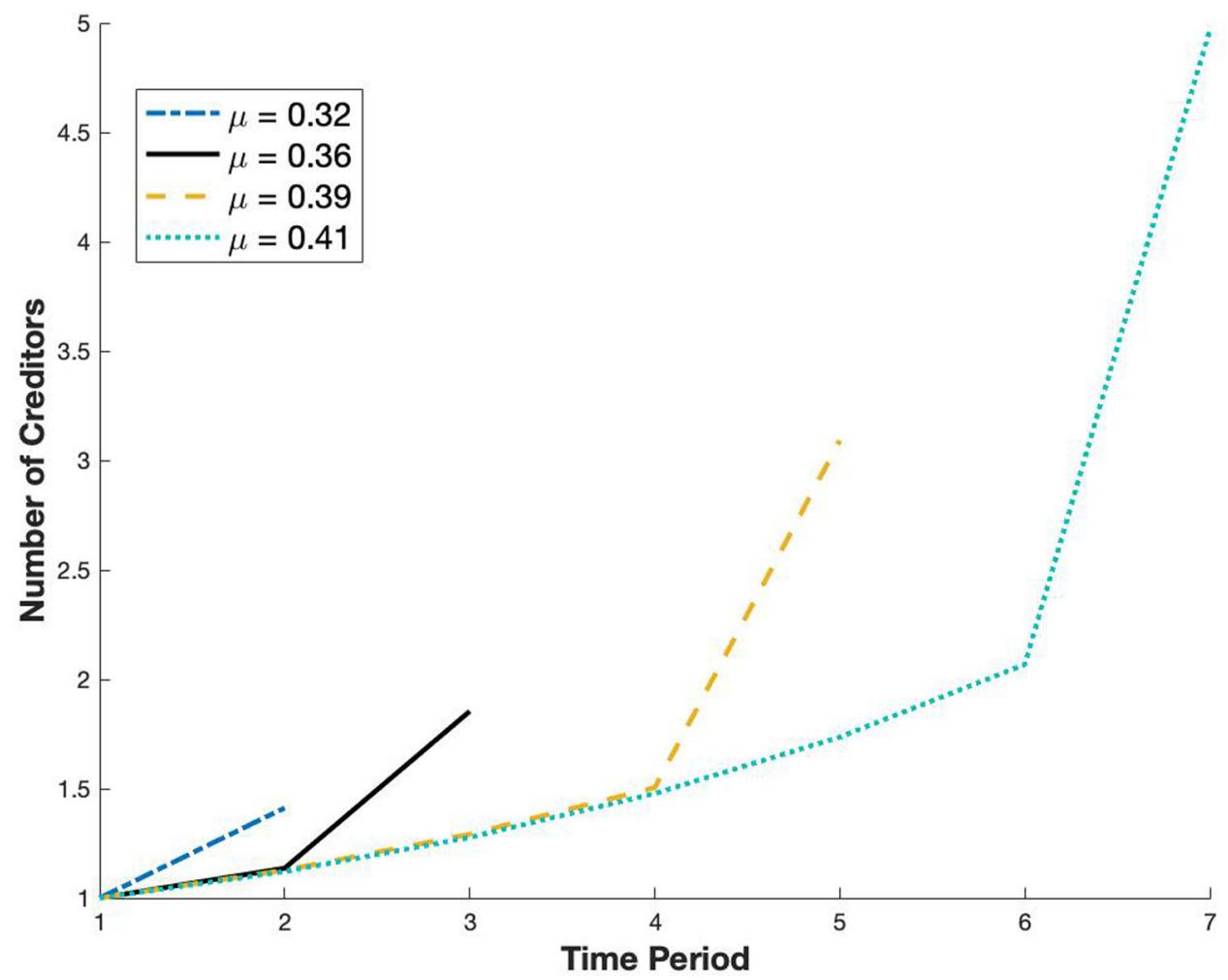

Figure 3. Creditor dynamics for firms with different growth rates. This figure plots the evolution of creditor dispersion $N_{t}$ for firms with growth rates $\mu=0.32,0.36,0.39$, and 0.41 . The number of creditors increases more slowly for firms with higher growth rates. In addition, highergrowth firms can survive longer and support a larger number of creditors. (Color figure can be viewed at wileyonlinelibrary.com)
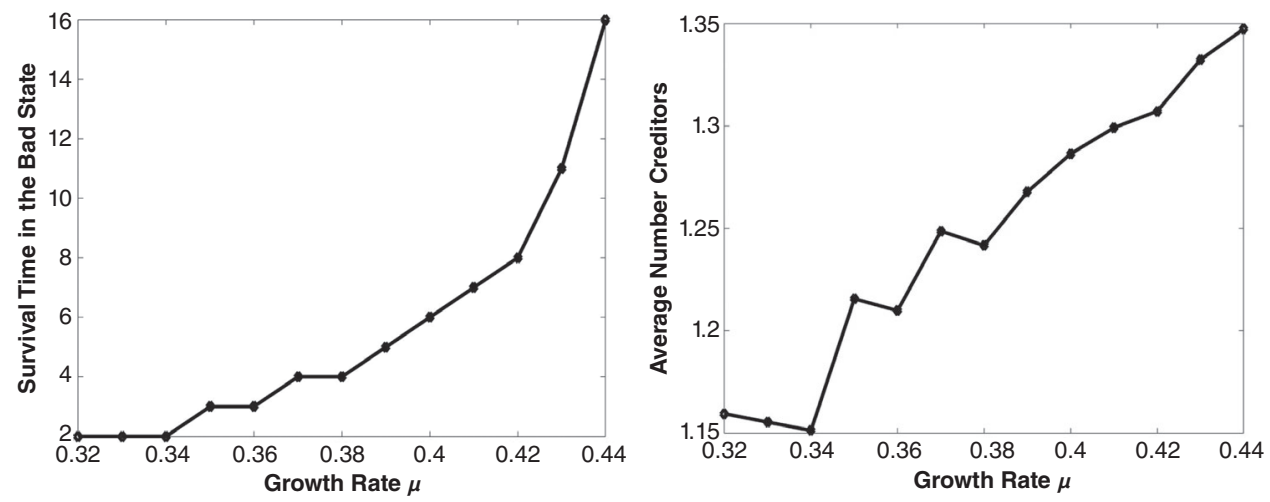

Figure 4. Average creditor dispersion for firms with different growth rates. The left panel plots the number of periods that a firm can survive in the bad state with different growth rates $(\mu=0.32,0.33,0.34, \ldots 0.44)$. The right panel plots the average number of creditors $E\left(N_{t}^{*}\right)$ given by (23) for firms with different growth rates. 
Next, for each firm with a given $\mu$, I calculate the probability-weightedaverage number of creditors,

$$
E\left(N_{t}^{*}\right)=\sum_{t=1}^{\tau_{L}} \frac{p(1-p)^{t-1}(1-\pi)^{t}}{\sum_{t=1}^{\tau_{L}} p(1-p)^{t-1}(1-\pi)^{t}} N_{t}^{*},
$$

where $\tau_{L}$ is the time of rollover failure if the state remains bad for sufficiently long. The weight $p(1-p)^{t-1}(1-\pi)^{t}$ is the unconditional probability that the state turns good in period $t$ and the project does not mature in or before period $t$. This average $E\left(N_{t}^{*}\right)$ proxies for the empirically observed number of creditors if firms enter the sample in the period when the good shock realizes, for example, when the fundamental is good enough to be documented by some data vender. To study how the growth rate $\mu$ affects the average creditor dispersion $E\left(N_{t}^{*}\right)$, I calculate (23) for $\mu=0.32,0.33, \ldots$, and 0.44 , and plot the results in the right panel of Figure 4 . The average number of creditors broadly increases as the growth rate $\mu$ increases. The driving effect is that higher-growth firms have larger debt capacity $\kappa^{B}$, which enables them to support more creditors and survive longer, as suggested by statement 1 in Corollary 3 . However, whenever $\mu$ increases without affecting the longevity of the firm, one can easily prove that the average dispersion decreases, reflecting statement 2 in Corollary $3: N_{t}$ increases more slowly in higher-growth firms. For example, in the left panel of Figure 4, when $\mu \in\{0.32,0.33,0.34\}, \mu \in\{0.35,0.36\}$, or $\mu \in\{0.37,0.38\}$, the firm can survive two, three, and four periods, respectively. Within each set, the average creditor dispersion $E\left(N_{t}^{*}\right)$ decreases with $\mu$ as shown in the right panel of Figure 4.

\section{B. Empirical Relevance}

The model's predictions relate to the empirical literature in three respects. First, the model predicts that firms often renegotiate their debt before declaring bankruptcy, which is supported by the empirical evidence in Roberts and Sufi (2009a, 2009b) and Roberts (2015). These authors show that in the event of a technical default, instead of an immediate termination of the lending relationship, $62.6 \%$ of borrowers receive waivers from creditors, $32.2 \%$ of loan contracts are renegotiated, and only $4.4 \%$ of loan contracts are terminated. In aggregate, $94 \%$ of the loans with maturity longer than three years are renegotiated, and the median renegotiated loan receives four renegotiations in its lifetime. In addition, related to the theoretical prediction that renegotiation lowers the debt that the firm carries forward, Roberts and Sufi (2009a) show that borrowers reduce net debt issuance following renegotiation.

Second, the sharp contrast between the time-series (see Corollary 2) and the cross-sectional (see Corollary 3) predictions reconciles seemingly contradictory empirical findings. On the one hand, the time-series prediction of creditor dispersion is consistent with empirical evidence in Farinha and Santos (2002) that firms are more likely to abandon a single-creditor structure when 
historical performance declines. ${ }^{13}$ More recently, Rauh and Sufi (2010) show that as credit quality deteriorates, firms introduce more heterogeneous debt capital. Specifically, fallen angels (firms downgraded from investment grade to speculative grade) move from having only senior unsecured debt to secured bank debt and subordinated bonds, which are more difficult to renegotiate. On the other hand, echoing the cross-sectional prediction that firms with higher growth can support more creditors, Houston and James (1996) find that firms with multiple relationship banks have significantly higher asset growth compared with their single-bank counterparts.

Third, the dynamic aspect of my model also helps connect some stylized facts on the cost of borrowing with the theoretical idea that creditor dispersion strengthens repayment incentives. Indeed, many classic papers (e.g., Berglöf and Von Thadden (1994), Bolton and Scharfstein (1996), and Diamond (2004)) build on the idea that dispersed creditor structure commits the borrowing firm to pay back its debt. This channel implies that the required interest rate should be lower when the firm's debt is more dispersedly held, because the difficulty inherent in renegotiating with dispersed creditors makes repayment more credible. However, Petersen and Rajan (1994, 1995) empirically document a significant positive association between a firm's number of creditors and its cost of credit. My model suggests that although borrowing from more creditors should reduce the required interest rate, firms do so only when their performance deteriorates, driving up the observed interest rate in equilibrium.

PREDiction 1: If $\lambda(1+\mu) \geq 1$, or $\lambda(1+\mu)<1$ and $N_{t+1}^{*} \geq \frac{1}{\lambda(1+\mu)}$, the optimal number of creditors $N_{t+1}^{*}$ and the interest rate $\frac{F_{t+1}^{*}}{D_{t+1}}$ covary positively in equilibrium.

The regularity conditions rule out a tedious special case that, together with the proof of this prediction, is discussed in Appendix A. In equilibrium, leverage $d_{t+1}$ determines the number of creditors $N_{t+1}^{*}$ as in (22): more creditors are needed to support higher leverage. Furthermore, firm leverage increases as the fundamental stays bad, driving up the cost of borrowing. Therefore, the optimal creditor dispersion and the equilibrium interest rate are positively correlated.

\section{Model Implications}

In this section, I offer two new insights based on my dynamic model. First, a large body of literature on debt assumes either a representative creditor or an exogenous number of creditors. Why is it important that firms dynamically choose creditor dispersion over time? In Section IV.A, I show that when the number of creditors is exogenously fixed, meaningful renegotiation can never occur in the bad state- the state in which debt renegotiation is most valuable.

Next, it is commonly accepted that dispersed debt ownership alleviates firms' commitment problems and thereby increases their debt capacity (e.g.,

13 The performance measures include liquidity, cash flow, leverage, and so on. 
Berglöf and Von Thadden (1994), Bolton and Scharfstein (1996), Hart and Moore (1998), Diamond (2004)). However, it is unclear how effective this mechanism is when commitment problems become severe in a dynamic world. In particular, if firms can frequently renegotiate their debt, will dispersed creditors still lead to extra pledgeability by allowing firms to borrow against better outcomes in the future? I address this question in Section IV.B. Perhaps surprisingly, I find that when renegotiation is frequent, a dispersed creditor structure no longer increases firms' pledgeability: the debt capacity in the bad state converges to the resale value $\lambda Y_{t}$, which can be attained in the limit by having only a single creditor.

\section{A. Impossibility of Renegotiation with Exogenous Creditor Dispersion}

To facilitate the discussion in this section, I extend the baseline model in Section I to allow for more frequent renegotiation. Specifically, I assume that each period lasts $\Delta t<1$, and the firm needs to roll over one-period debt with $\Delta t$ maturity until the project matures. The firm can renegotiate the repayment each time the debt matures. ${ }^{14}$ In each period, the project matures with probability $\pi \Delta t$, a bad state switches to a good one with probability $p \Delta t$, the discount rate is $r \Delta t$, and the growth rate of the fundamental process $Y_{t}$ is $\mu \Delta t$. All other model ingredients are the same as in Section I. When $\Delta t=1$, this specification is exactly the same as in the baseline model..$^{15}$

Similar to (1), the first-best firm value in the good state after the $\Delta t$ modification is

$$
\hat{v}_{F B}^{G}=\frac{\pi \Delta t}{(1+r \Delta t)-(1-\pi \Delta t)(1+\mu \Delta t)}=\frac{\pi}{r-\mu+\pi+\pi \mu \Delta t} .
$$

When $\Delta t \rightarrow 0$, this first-best value approaches its continuous-time limit $\frac{\pi}{r-\mu+\pi}$. To ensure finite values, I assume $r>\mu-\pi$ in this section.

The main objective of this subsection is to characterize the debt capacity with any exogenously fixed number of creditors, that is, $N_{t} \equiv N$ for all $t$ and some constant $N$, and to show that no meaningful renegotiation can exist in equilibrium. The key difference relative to the baseline model is that the firm cannot adjust the number of creditors over time. Therefore, the renegotiated repayment $\min \left(F_{t}, N \lambda Y_{t+1}\right)$ must be refinanced by the same number of creditors $N$. Hence, similar to but different from (12) in the baseline model, debt rollover is successful whenever

$$
\min \left(F_{t}, N \lambda Y_{t+1}\right) \leq \hat{D C_{N}^{z+1}}\left(Y_{t+1}\right),
$$

\footnotetext{
14 Alternatively, the firm can have multiple renegotiations before maturity. The results are the same qualitatively, with added mathematical complexity because renegotiation dates and maturity dates are different.

15 One can also use the continuous-time analogue of the variables, for example, maturing intensity $1-e^{-\pi \Delta t}$, discount factor $e^{-r \Delta t}$, state-switching intensity $1-e^{-p \Delta t}$, and growth rate $e^{\mu \Delta t}-1$. When $\Delta t$ is small, these numbers converge to the linearization that I use in the main text.
} 
where the debt capacity $\hat{D C}_{N}^{z_{t+1}}\left(Y_{t+1}\right)$ with exogenously fixed $N$ is given by

$$
\begin{aligned}
& \hat{D C}_{N}^{z_{t}}\left(Y_{t}\right)=\max _{F_{t}} \frac{1}{1+r}\{\underbrace{\pi \min \left(F_{t}, Y_{t}\right)}_{\text {project matures }} \\
& +(1-\pi) E_{t}[\underbrace{\left[\mathbf{1}_{\min \left(F_{t}, N \lambda Y_{t+1}\right) \leq \hat{D} \hat{C}_{N}^{z_{t+1}}\left(Y_{t+1}\right)} \min \left(F_{t}, N \lambda Y_{t+1}\right)\right.}_{\text {successful rollover }} \\
& +\underbrace{\left.\mathbf{1}_{\min \left(F_{t}, N \lambda Y_{t+1}\right)>\hat{D C_{N}^{z}}{ }^{z+1}\left(Y_{t+1}\right)} \min \left(F_{t}, \lambda Y_{t+1}\right)\right]}_{\text {rollover failure }}\} .
\end{aligned}
$$

The linear debt capacity $\hat{D C}_{N}^{z_{t}}\left(Y_{t}\right)=\hat{\kappa}_{N}^{z_{t}} Y_{t}$ is characterized in the following proposition. Compared with Corollary 1 in the baseline model, when creditor dispersion $N_{t}$ is exogenously fixed, debt capacity in the bad state is always achieved by having premature termination.

Proposition 3. (Debt capacity with exogenous creditor dispersion): Suppose $N_{t} \equiv N$ for all $t$ and $\hat{v}_{F B}^{G} \geq 1$. Then debt capacity is given by

$$
\hat{\kappa}_{N}^{G}=\frac{1}{1+r \Delta t}\left[\pi \Delta t+(1-\pi \Delta t)(1+\mu \Delta t) \lambda \min \left(N, \frac{\hat{v}_{F B}^{G}}{\lambda}\right)\right]
$$

and

$$
\begin{aligned}
\widehat{\kappa}_{N}^{B} & =\frac{1}{1+r \Delta t}\left\{\pi \Delta t+(1-\pi \Delta t)\left[p \Delta t \min \left(\widehat{v}_{F B}^{G}, \lambda N\right)(1+\mu \Delta t)\right)\right) \\
& ((+(1-p \Delta t) \lambda]\} .
\end{aligned}
$$

The rationale for the debt capacity in the good state is conceptually identical to that for Corollary 1 . The firm can commit to pay back $N \lambda(1+\mu \Delta t) Y_{t}$ up to the entire first-best firm value $\hat{v}_{F B}^{G}(1+\mu \Delta t) Y_{t}$. The added complication with $N$ being exogenously fixed is that this repayment can be refinanced by having $N$ creditors again, a point I verify in Appendix A. Since the fundamental following a good-state realization is deterministic, renegotiation is largely inconsequential. ${ }^{16}$

The bad state is more interesting. When the firm cannot adjust creditor dispersion $N$, the debt capacity is always achieved by having rollover failure in the bad state even with concentrated creditor structure ( is counterintuitive. Recall from Corollary 1 in the baseline model that when

\footnotetext{
${ }^{16}$ Renegotiation only occurs in the special case in which $\lambda N(1+\mu \Delta t)<1$ and the firm schedules a repayment $F_{t} \in\left(\lambda N(1+\mu \Delta t) Y_{t}, Y_{t}\right]$ in order to pledge the final dividend when the project matures.
} 
$N$ is small enough $\left(N \leq \frac{\kappa^{B}}{\lambda}\right)$, debt rollover is always successful: the renegotiated repayment of $\lambda N Y_{t} \leq \kappa^{B} Y_{t}$ can always be refinanced. Why is renegotiation no longer possible when the number of creditors is exogenously fixed? This is because, to raise the renegotiated payment, the firm must increase creditor dispersion to make future repayments more credible (recall Corollary 2). When this option is infeasible, the firm has no choice but to suffer rollover failure in the bad state. Put differently, the renegotiated payment with $N$ creditors cannot be refinanced by $N$ creditors again, that is, $\lambda N Y_{t}>\hat{\kappa}_{N}^{B} Y_{t}$. As a result, there is no meaningful renegotiation in the bad state when the number of creditors is exogenously fixed, a consequence of the dynamic nature of the model.

It is worth pointing out that many bankruptcy procedures designed to coordinate creditors may backfire. ${ }^{17}$ While promoting the efficient outcome in the bankruptcy state, these procedures also reduce firms' commitment power ex ante. In the model, imposing an efficient ex post renegotiation is equivalent to having a single creditor exogenously. The calculation of debt capacity in (28) shows that no meaningful renegotiation can occur in the bad state even with a single creditor, and hence firms are terminated sooner. This is an unintended side effect when ex post coordination failure is eliminated.

\section{B. Vanishing Debt Capacity with Frequent Renegotiation}

In this subsection, I study the effect of renegotiation frequency on the debt rollover process. If renegotiation rarely occurs, then the commitment friction disappears and the first-best firm value can be restored. Therefore, in the remainder of this section, I focus on the limiting case $\Delta t \rightarrow 0$ as it proxies for frequent renegotiation. When a firm only borrows from a single creditor, $N_{t}=1$, the maximum repayment if the project does not mature in period $t$ is $\lambda Y_{t+\Delta t}$, which approaches $\lambda Y_{t}$ when the period length is very short, $\Delta t \rightarrow 0$. Because in the limit both the discount rate and the probability that the project matures are negligible, the debt capacity with a single creditor approaches $\lambda Y_{t} .{ }^{18}$ Proposition 4, which is also the main result of this section, shows that when debt renegotiations are frequent, having dispersed creditors becomes irrelevant: the debt capacity associated with any number of creditors approaches $\lambda Y_{t}$ as well.

Proposition 4. (Renegotiation frequency): The debt capacities in the bad state converge to the resale value uniformly as renegotiation becomes very frequent. Mathematically, for any exogenously fixed $N$,

$$
\lim _{\Delta t \rightarrow 0} \hat{\kappa}_{N}^{B}=\lambda .
$$

\footnotetext{
${ }^{17}$ Well-known procedures include the automatic stay clause, Chapter 11 reorganization, and the aforementioned "avoidable preference" clause.

${ }^{18}$ See equation (28) with $\Delta t \rightarrow 0$ for exogenously fixed $N_{t} \equiv 1$ or Corollary 1 with $r, \pi, p$, and $\mu \rightarrow 0$ for endogenous $N_{t}=1$.
} 
In addition, when $\Delta t$ is sufficiently small, the total debt capacity in the bad state is given by

$$
\kappa^{B}=\frac{1}{1+r \Delta t}\left\{\pi \Delta t+(1-\pi \Delta t)\left[p \Delta t \kappa^{G}(1+\mu \Delta t)+(1-p \Delta t) \lambda\right]\right\},
$$

which also approaches $\lambda$ as $\Delta t \rightarrow 0$.

The debt capacity in (29) inherits the baseline version (16). To understand the intuition of Proposition 4, recall that the benefit of having dispersed creditors is to allow the firm to borrow against the potential value improvements in the next period if the good shock arrives. In doing so, the firm risks termination should the bad state persist. When renegotiation becomes extremely frequent $(\Delta t \rightarrow 0)$, the probability of the fundamental switching to a good state $(p \Delta t)$ converges to zero. Consequently, the upside benefit materializes with a negligible probability and the downside rollover risk almost certainly occurs. As a result, the debt capacity in (28) and (29) converges to $\lambda$, the debt capacity with a single creditor.

I would like to emphasize that the essence of Proposition 4 crucially relies on the dynamic nature of debt rollover. In the simplified static model in Appendix B, one can also let the probability of realizing the good state approach zero, in which case the firm's debt capacity ex ante declines similar to Proposition 4. However, this comparative static exercise is conceptually different. Reducing the likelihood of the good outcome in a static model necessarily lowers the quality of the project. Therefore, the lower debt capacity results mechanically because the project is not as valuable to begin with. In contrast, throughout the dynamic analysis in this section, the first-best firm value is held constant in the limit and does not shrink to the resale value. Another way to interpret Proposition 4 is that even in the limit when renegotiation occurs frequently, the (expected) upside remains the same, but the firm cannot borrow against it by having multiple creditors.

Since troubled firms renegotiate debt at or before maturity, the renegotiation cycle must be shorter than debt maturity in practice. Therefore, if debt maturity is shorter, renegotiations tend to occur more often. The analysis above suggests that for a debt instrument with very short maturity, such as a repo agreement, the threat of incurring rollover risk and coordination failures among multiple lenders cannot improve borrowers' debt capacity. This may be one reason why repo lenders often receive super-seniority in bankruptcy proceedings.

It is also interesting to relate my analysis to the classic work of Diamond and Rajan (2001), who show that coordination problems among short-term dispersed depositors (creditors) can improve a bank's (borrower's) pledgeability. My paper differs in two important respects. First, the dynamic feature in this paper separates two crucial ingredients in the static Diamond-Rajan mechanism: the coordination problem among creditors and the short maturity of debt. While the coordination problem creates a termination threat that improves pledgeability (Proposition 3), the short maturity can lead to more 
frequent renegotiation that exacerbates the commitment problem. Second, the stochastic fundamental process in this paper extends the static insight from Diamond and Rajan (2001). In a dynamic model with a stochastic fundamental, frequent renegotiation increases the likelihood that a bad state will persist before the next round of renegotiation. This higher persistence of the bad state, which is absent in a static model, dramatically increases rollover risk, which in turn severely limits the commitment power associated with a dispersed creditor structure.

In the model, I analyze exogenous renegotiation frequency. In practice, however, a borrowing firm chooses when to renegotiate with its creditors. While I leave the full interaction between creditor dispersion and endogenous renegotiation timing for future research, I conjecture that firms have incentives to renegotiate instantaneously if they cannot commit to an exogenous debt renegotiation schedule. Because debt renegotiation is beneficial for the borrowing firm ex post, without commitment, the firm may have incentives to abuse it. Therefore, the limiting case discussed in this section could represent the outcome when firms cannot commit to the timing of renegotiations.

\section{The Role of Cash}

So far, I have assumed that the firm always refinances the exact amount of debt repayment and never carries cash across periods. In this section, I relax this restriction and study the role of cash when the firm borrows from multiple creditors. In Section V.A, I extend the baseline model in Section I to allow for cash savings by the firm. As a benchmark, I show in Section V.B that the ability to save cash is irrelevant whenever the firm borrows from a single creditor. In Section V.C, I demonstrate a novel insight: cash combined with multiple creditors can increase state-noncontingent commitment power. Consequently, firms only keep cash if debt capacity has a positive state-noncontingent component.

\section{A. Extended Model with Cash Savings Inside the Firm}

I begin with a modified version of the baseline model that accommodates cash. Denote by $C_{t}$ the firm's cash holding upon entering period $t$, which is the extra state variable. Assume that the interest rate on cash is the same as the discount rate $r$. If the project matures in period $t$, then total firm value, including both the project's payoff and cash, is $Y_{t}+C_{t}$. If sold prematurely, total firm value is $L_{t}\left(Y_{t+1}\right)+C_{t}$, where $L_{t}$ is the resale value of the assets. ${ }^{19}$ This specification extends the baseline model in which $L_{t}\left(Y_{t+1}\right)=\lambda Y_{t+1}$. As a result of the extra cash balance in a renegotiation, the firm must offer

$$
\min \left(\frac{F_{t}}{N_{t}}, L_{t}\left(Y_{t+1}\right)+C_{t}\right),
$$

\footnotetext{
19 The assumption on the firm's resale value is the crucial difference from Hart and Moore (1998). They assume that the liquidation value is unaffected by the firm's cash holding, whereas I assume the cash is part of the assets that can be seized by creditors.
} 
similar to the logic of (4). Therefore, the value of debt in (7) becomes

$$
\begin{aligned}
D_{t} & =\frac{1}{1+r}\{\underbrace{\pi \min \left(F_{t}, Y_{t}+C_{t}\right)}_{\text {project matures }}+(1-\pi) E_{t}[\underbrace{\mathbf{1}_{R O} \min \left(F_{t}, N_{t}\left(L_{t}+C_{t}\right)\right)}_{\text {successful rollover }} \\
& +\underbrace{\left(1-\mathbf{1}_{R O}\right) \min \left(F_{t}, L_{t}+C_{t}\right)}_{\text {rollover failure }}]\} .
\end{aligned}
$$

At the refinancing stage in period $t$, the debt capacity net of the cash balance is

$$
D C_{t+1} \equiv \max _{C_{t+1}, N_{t+1}, F_{t+1}} D_{t+1}-\frac{C_{t+1}}{1+r}
$$

Similar to but different from definition (11) in the baseline model, the net borrowing amount $D_{t+1}-\frac{C_{t+1}}{1+r}$ is what can be used to repay the maturing creditors in period $t$. Together with the existing cash $C_{t}$, the total resources available for repayment in period $t$ are $D C_{t+1}+C_{t}$. Similar to (12), debt rollover is successful $\left(\mathbf{1}_{R O}=1\right)$ if the total renegotiated repayments from (30) can be honored,

$$
\min \left(F_{t}, N_{t}\left(L_{t}+C_{t}\right)\right) \leq D C_{t+1}+C_{t} .
$$

At the refinancing stage in period $t$, the firm chooses cash $C_{t+1}$, number of creditors $N_{t+1}$, and face value $F_{t+1}$ to maximize equity value $V_{t+1}$, which is recursively defined as

$$
\begin{aligned}
& V_{t}=\frac{1}{1+r}\{\underbrace{\pi \max \left(Y_{t}+C_{t}-F_{t}, 0\right)}_{\text {project matures }}+(1-\pi) E_{t}\left[\mathbf{1}_{R O}\right. \\
& \underbrace{\max _{t+1}, N_{t+1}, F_{t+1}}_{\text {successful rollover }} V_{N_{t+1}}^{z_{t+1}\left(C_{t+1}, F_{t+1}, Y_{t+1}\right)}+\underbrace{\left(1-\mathbf{1}_{R O}\right) \max \left(L_{t}+C_{t}-F_{t}, 0\right)}_{\text {rollover failure }}]\},
\end{aligned}
$$

where $\left(C_{t+1}, N_{t+1}, F_{t+1}\right)$ satisfy

$$
\frac{C_{t+1}}{1+r}=D_{N_{t+1}}^{z_{t+1}}\left(C_{t+1}, F_{t+1}, Y_{t+1}\right)-\min \left(F_{t}, N_{t}\left(L_{t}+C_{t}\right)\right)+C_{t}
$$

The evolution of cash (35) states that the present value of the cash carried into the next period $\frac{C_{t+1}}{1+r}$ comes from the newly issued debt $D_{t+1}$ and the cash balance $C_{t}$, net of the repayments made to the maturing creditors, $\min \left(F_{t}, N_{t}\left(L_{t}+C_{t}\right)\right)$. The equilibrium variables of interest are the firms' 
refinancing decisions $\left(C_{t+1}^{*}, N_{t+1}^{*}, F_{t+1}^{*}\right)$ that govern the evolution of cash balance, creditor dispersion, and face value.

\section{B. Absence of Cash with a Single Creditor}

I first show that cash is redundant whenever the firm borrows/refinances from a single creditor. The result, summarized in Proposition 5, is highly robust in that it does not depend on a specific fundamental process $Y_{t}$ or a functional form of the resale value $L_{t}\left(Y_{t+1}\right)$.

PROposition 5. (Redundancy of cash with a single creditor): In any period $t$, if the firm chooses a single creditor $N_{t} \equiv 1$, equilibrium can be implemented with no cash: $C_{t}=0$.

The intuition for Proposition 5 is that both the firm and the creditor are indifferent about who holds the cash: the marginal loan granted in period $t-1$ for the extra cash balance of $\frac{C_{t}}{1+r}$ is risk-free for any $C_{t}$. Since the cash balance $C_{t}$ in period $t$ is part of the liquidation value that can be seized by the creditor, the creditor is happy to lend the present value of $\frac{C_{t}}{1+r}$ in period $t-1$. Alternatively, the firm can choose not to borrow the extra cash and lower the face value by $C_{t}$. The creditor's payoff is likewise not affected. Hence, the ability to borrow extra cash is inconsequential with a single creditor.

The following example illustrates the logic of Proposition 5. In addition, this example shows that cash combined with multiple creditors improves pledgeability.

ExAmple 1. (A deterministic example): There are three periods, $t=0,1,2$, and no time discount, $r=0$. The project matures at $t=2$ with certainty, and the final dividend $Y_{2}$ is deterministic. The firm issues one-period debt in period 0 to finance the upfront investment $I_{0}$ and rolls over the maturing debt in period 1 . The resale value of the project at the interim date is $L_{1}=0$.

In this example, if the firm cannot borrow more than $I_{0}$ and keep some cash, the total pledgeable income is zero. No project with positive investment $\left(I_{0}>0\right)$ can be financed. This is because $L_{1}=0$, and each creditor receives $\min \left(\frac{F_{1}}{N_{1}}, L_{1}\right)=0$ in a renegotiation. Any one-period debt issued in period 0 will be completely renegotiated away in period 1, despite the firm's ability to refinance $Y_{2}$. In anticipation of this outcome, creditors refuse to lend regardless of creditor dispersion $N_{1}$ and face value $F_{1}$.

When the firm borrows from a single creditor $N_{1}=1$, even if cash savings are allowed, the pledgeable income is still zero. To see this, suppose the firm borrows $I+C_{1}$ by promising some face value $F_{1}$. When the debt matures in period 1 , the repayment is renegotiated to $\min \left(F_{1}, L_{1}+C_{1}\right) \leq C_{1}$. Therefore, a single creditor can never break even.

Once the firm can borrow extra cash from multiple creditors, $N_{1}>1$, any positive net present value project with $I_{0} \leq Y_{2}$ can be financed. Specifically, in period 0 , the firm can raise $I_{0}+C_{1}$ risk-free debt by promising a total 
repayment of $F_{1}=I_{0}+C_{1}$ to $N_{1}$ creditors, where

$$
C_{1}=\frac{Y_{2}+I_{0}}{N_{1}-1}
$$

After making the investment $I_{0}$, the firm keeps $C_{1}$ as cash. In period 1 , the firm must offer

$$
\min \left(\frac{F_{1}}{N_{1}}, L_{1}+C_{1}\right)=\min \left(\frac{I_{0}+C_{1}}{N_{1}}, C_{1}\right)=\frac{I_{0}+C_{1}}{N_{1}}
$$

to each creditor. ${ }^{20}$ The firm can therefore commit to pay back a total of $I_{0}+$ $C_{1}$ to $N_{1}$ creditors. This repayment can be honored by paying back the cash balance $C_{1}$ and refinancing the remaining $I_{0} \leq Y_{2}$ into the final period.

Example 1 shows that cash in the firm improves each creditor's reservation payoff from zero to $C_{1}$. As a result, if renegotiated in period 1 , the total committed repayment to the $N_{1}$ creditors is $N_{1} C_{1}$, which is higher than the available cash $C_{1}$ inside the firm. This wedge $\left(N_{1}-1\right) C_{1}$, which equals $I_{0}+Y_{2}$ in Example 1, creates pledgeability because it commits the firm to borrow against the final dividend and credibly repay it to the initial creditors. This observation suggests that the role of cash in this debt rollover model is very different from that in Hart and Moore (1998), where cash is used to reduce partial liquidation in the states in which liquidation is relatively more inefficient. The next subsection pinpoints the source of cash-induced pledgeability when the fundamental is stochastic.

\section{Cash with Multiple Creditors}

In this subsection, I examine the role of cash when there are multiple creditors. From (30), the total payment after renegotiation is $\min \left(F_{t}, N_{t}\left(L_{t}+C_{t}\right)\right)$, and the pledgeable repayment $N_{t} L_{t}+N_{t} C_{t}$ contains two components. The first component $N_{t} L_{t}\left(Y_{t+1}\right)$ depends on the realization of $Y_{t+1}$, increasing the firm's state-contingent commitment power. In contrast, the second component from the cash balance $N_{t} C_{t}$ is independent of $Y_{t+1}$, increasing the state-noncontingent commitment power. Example 2 shows that firms choose to borrow extra money and carry a cash balance when the debt capacity has a positive state-noncontingent component.

ExAmple 2. (A stochastic example): There are three periods, $t=0,1,2$. The project matures at $t=2$. There are two equally likely states in period 1 ( $z=$ $G, B$ ), with the corresponding resale value $L_{1}^{z}$ and final dividend $Y_{2}^{z}$ specified as follows:

\footnotetext{
${ }^{20}$ Note that a simple rearrangement of (36) gives $N_{1} C_{1}=I_{0}+C_{1}+Y_{2}$, implying that $\frac{I_{0}+C_{1}}{N_{1}}<$ $C_{1}$.
} 
Table

\begin{tabular}{lcc}
\hline & $L_{1}^{z}$ & $Y_{2}^{z}$ \\
\hline$G($ ood $)$ & 2 & $X$ \\
$B(a d)$ & 1 & 5 \\
\hline
\end{tabular}

Case $1: X=10$. In this case, the debt capacity in period $1\left(Y_{2}^{z}\right)$ is proportional to the resale value, $Y_{2}^{z}=5 L_{1}^{z}$, and there is no state-noncontingent component in $Y_{2}^{z}$. Hence, the firm can pledge the entire final dividend $Y_{2}^{z}$ in period 0 by using only dispersed creditors without cash: by borrowing from $N_{1}=\frac{Y_{2}^{z}}{L_{1}^{z}}=5$ creditors and promising a total face value of $F_{1}=10$, the firm can pledge the entire final dividend. Mathematically, $\min \left(N_{1} L_{1}^{z}, F_{1}\right)=N_{1} L_{1}^{z}=Y_{2}^{z}$. Therefore, no cash is needed.

Case 2: $X=7 .{ }^{21}$ In this case, I show that the firm can design a pair of $\left(N_{1}, C_{1}\right)$ to pledge the entire final dividend. To do so, the total renegotiated payment in period 1 must be exactly the final dividend plus the cash balance $C_{1}$,

$$
N_{1} L_{1}^{z}+N_{1} C_{1}=Y_{2}^{z}+C_{1} .
$$

Plug in the numbers for each state $z=G, B$ and solve for $\left(N_{1}, C_{1}\right)=(2,3)$.

To borrow the entire final dividend $\frac{Y_{2}^{G}+Y_{2}^{B}}{2}=6$ in period 0 , the firm borrows a total of $6+C_{1}=9$ from $N_{1}=2$ creditors and keeps $C_{1}=3$ as cash. The total face value promised to the creditors is $Y_{2}^{G}+C_{1}=10$. In the good state, there is no renegotiation because the reservation value of each creditor is $L_{1}^{G}+C_{1}=5$. To repay 10, the firm uses up the cash balance 3 and refinances the remaining 7 , which coincides with the final dividend $Y_{2}^{G}$. In the bad state, the actual repayment to each creditor is renegotiated to $L_{1}^{B}+C_{1}=4$. The total repayment of 8 is honored by using cash $C_{1}$ and final dividend $Y_{2}^{B}$. In period 0 , the expected repayment is $\frac{10+8}{2}=9$, making the creditors break even.

From a more general perspective, the debt capacity in this case can be decomposed into state-contingent and noncontingent components,

$$
Y_{2}^{z}=2 L_{1}^{z}+(3,3)
$$

Compared with (38), one can see that the state-contingent component $2 L_{1}^{z}$ is pledged by having $N_{1}=2$ creditors, and the state-noncontingent component 3 is pledged by having cash savings inside the company.

Case $3: X>10$. In this case,

$$
\frac{Y_{2}^{G}}{Y_{2}^{B}}=\frac{X}{5}>\frac{L_{1}^{G}}{L_{1}^{B}}=2
$$

and there is no role for cash: any outcome can be implemented without keeping cash. Take $X=15$ for instance. Similar to (39), the final dividend $Y_{2}^{z}$ can be

${ }^{21}$ In fact, any $X \in(6,10)$ delivers a qualitatively similar outcome. 
decomposed into two components,

$$
Y_{2}^{z}=(15,5)=10 *(2,1)+(-5,-5)=10 * L_{1}^{z}+(-5,-5) .
$$

To pledge the entire final dividend, the cash savings must be negative. In fact, solving (38) gives $\left(N_{1}, C_{1}\right)=\left(10,-\frac{5}{9}\right)$. Hence, any positive cash balance reduces pledgeability.

Example 2 helps explain why firms save cash. If debt capacity contains a positive state-independent component, then firms can borrow extra cash to increase commitment power uniformly across all states and pledge this component to the creditors. In contrast, if the debt capacity is more state-sensitive than the resale value, there may not be a positive state-independent component and the firm never borrows extra cash. For instance, in the baseline model, firms can refinance up to the debt capacity $\kappa^{z} Y_{t} z$, which is more statesensitive than the resale value $\lambda Y_{t} z$ :

$$
\frac{\kappa^{G} Y_{t}(1+\mu)}{\kappa^{B} Y_{t}}>\frac{\lambda Y_{t}(1+\mu)}{\lambda Y_{t}} .
$$

Hence, assuming away cash savings in the baseline model is without loss of generality, a result formally established in the following proposition.

Proposition 6. (No cash holding in the baseline model): The firm never borrows extra cash in the baseline model, even when doing so is allowed, that is, $C_{t}^{*}=0$.

Despite being a nonexistence result, Proposition 6 highlights a new possibility for future research on firms' cash holding: adopting a more sophisticated fundamental process. For example, with a mean-reverting process, the project's expected profitability can be negatively correlated with the current state. Consequently, condition (40) could fail and cash savings can emerge in equilibrium. Many interesting questions await future research. For example, when do firms keep cash and how does it vary with cash flow distribution, how does cash holding interact with creditor dispersion, and how do firm characteristics affect the dynamics of cash accumulation?

\section{Conclusion}

In this paper, I construct a dynamic model in which the firm must repeatedly roll over short-term debt contracts in order to finance a long-term project. The firm cannot commit to make repayments but instead has incentives to opportunistically renegotiate the debt contracts. A dispersed creditor structure risks inefficient coordination problems among creditors, which, following bad shocks, makes it harder for a firm to restructure its debt and avoid liquidation. With a good shock realization, however, these same coordination problems enhance repayment incentives by making it harder for a firm to opportunistically hold up its creditors. In the model, the firm optimally chooses the number of 
creditors over time by trading off the benefit of better commitment power against the cost of elevated rollover risk.

The analysis shows that in the time series, firms increase the number of creditors after poor performance, whereas in the cross section, firms with higher growth rates can have more creditors on average. If firms cannot adjust their creditor dispersion over time, then no meaningful renegotiation can occur in equilibrium. In addition, frequent renegotiation destroys the extra pledgeability generated by a dispersed creditor structure. However, holding a cash balance while borrowing from multiple creditors can improve a firm's ability to pledge state-noncontingent borrowing capacity.

I conclude the paper with several potential directions for future research. First, one could endogenize renegotiation timing (or similarly, maturity profile) together with creditor structure. I offer some preliminary conjectures on this question at the end of Section IV, but a more comprehensive investigation can be informative. Second, how a firm's cash holding evolves remains an open question. The analysis in Section $\mathrm{V}$ points out that one must consider a more general fundamental process. Addressing this question could deliver new insights on how a firm's cash holding varies over time and how it is affected by the firm's creditor structure. Lastly, throughout the paper, I assume that the resale value of the project $\lambda Y$ is sufficiently small that continuing the project is always efficient. With a different specification, abandoning the project could be optimal in certain states of the world. Consequently, creditor structure could affect firms' incentive to continue the project (e.g., risk shifting and debt overhang). How creditor structure affects firms' investment decisions thus represents a potentially fruitful direction for future research.

Initial submission: April 1, 2016; Accepted: April 1, 2019

Editors: Stefan Nagel, Philip Bond, Amit Seru, and Wei Xiong

\section{Appendix A: Omitted Proofs}

PROOF OF EQUATION 1: The expected values of the final dividend satisfy the recursive formulation

$$
\begin{aligned}
& V_{F B}^{G}(Y)=\frac{1}{1+r}\left[\pi Y+(1-\pi) V_{F B}^{G}(Y(1+\mu))\right] \\
& V_{F B}^{B}(Y)=\frac{1}{1+r}\left\{\pi Y+(1-\pi)\left[p V_{F B}^{G}(Y(1+\mu))+(1-p) V_{F B}^{B}(Y)\right]\right\} .
\end{aligned}
$$

I conjecture and verify a linear solution: $V_{F B}^{\theta}(Y)=v_{F B}^{\theta} Y$. Under the conjecture, (A1) becomes

$$
\begin{aligned}
& v_{F B}^{G}=\frac{1}{1+r}\left[\pi+(1-\pi) v_{F B}^{G}(1+\mu)\right] \\
& v_{F B}^{B}=\frac{1}{1+r}\left\{\pi+(1-\pi)\left[p v_{F B}^{G}(1+\mu)+(1-p) v_{F B}^{B}\right]\right\}
\end{aligned}
$$

Solving the above system for $\left(v_{F B}^{G}, v_{F B}^{B}\right)$ gives (1).

Proof of Proposition 1: As discussed in the main text, the proof focuses on the bad state. I first show that the debt capacity $\kappa^{B} Y_{t}$ can only be attained by 
$N_{t}=\frac{\kappa^{G}}{\lambda}$ or $N_{t}=\frac{\kappa^{B}}{\lambda}$. Otherwise, I can construct an alternative creditor structure $\left(N_{t}^{\prime}, F_{t}^{\prime}\right)$ with a strictly higher debt value as follows.

(1) Consider any debt structure such that rollover fails in the bad state. The maximum payoff when the project matures is $Y_{t}$ and the maximum payoff from a good state is $\kappa^{G}(1+\mu) Y_{t}$. Therefore, the value of debt must be bounded by

$$
\frac{1}{1+r}\left\{\pi+(1-\pi)\left[p \kappa^{G}(1+\mu)+(1-p) \lambda\right]\right\} Y_{t}
$$

which can be attained by the creditor structure with $N_{t}=\frac{\kappa^{G}}{\lambda}$ and $F_{t}=$ $\max \left(Y_{t}, \lambda N_{t} Y_{t}(1+\mu)\right)$.

(2) Consider any debt structure such that rollover is successful in the bad state: $\min \left(F_{t}, \lambda N_{t} Y_{t}\right) \leq \kappa^{B} Y_{t}$. If $N_{t}<\frac{\kappa^{B}}{\lambda}$, then the renegotiated repayment $\min \left(F_{t}, \lambda N_{t} Y_{t+1}\right)$ is strictly less than $\kappa^{B} Y_{t+1}$. Setting $F_{t}^{\prime}=$ $\max \left(F, Y_{t}, \kappa^{G} Y_{t}(1+\mu)\right)$ and $N_{t}^{\prime}=\frac{\kappa^{B}}{\lambda}$ attains the value of debt as in (17). If $N_{t}>\frac{\kappa^{B}}{\lambda}$, then it must be the case that $F_{t}<\kappa^{B} Y_{t}$, which implies the renegotiated repayment $\min \left(F_{t}, \lambda N_{t} Y_{t+1}\right)=F_{t}$ regardless of the state. The same debt structure $\left(N_{t}^{\prime}, F_{t}^{\prime}\right)$ as above again increases the payoff to creditors uniformly when debt matures.

Hence, the debt capacity $\kappa^{B} Y_{t}$ can only be attained by $N_{t}=\frac{\kappa^{G}}{\lambda}$ (as in (A3), or equivalently (16)) or $N_{t}=\frac{\kappa^{B}}{\lambda}$ (as in (17)). Next, I show that the former dominates the latter. Suppose that $\kappa^{B} Y_{t}$ is attained by (17) instead of (16),

$$
\kappa^{B}=\frac{1}{1+r}\left\{\pi+(1-\pi)[p(1+\mu)+1-p] \kappa^{B}\right\} .
$$

Subtracting the equation above from (14) yields

$$
\lambda-\kappa^{B}>\frac{1}{1+r}\left[\pi+(1-\pi)[p(1+\mu)+1-p]\left(\lambda-\kappa^{B}\right)\right] .
$$

Since

$$
1+r>(1-\pi)(1+\mu)>(1-\pi)[p(1+\mu)+1-p]
$$

inequality (A4) implies that $\kappa^{B}<\lambda$, which is smaller than $\kappa^{G}$. However, these results then imply (17) is strictly dominated by (16) - a contradiction. Hence, condition (16) gives the debt capacity in the bad state, completing the proof.

The more precise statement of Proposition 2: Assume that $\lambda(1+\mu)<1$. Suppose the firm needs to refinance leverage of $d_{t+1}$ at the refinancing stage in period $t$. If the realized state is $\operatorname{good}\left(z_{t+1}=1+\mu\right)$, then the new number of 
creditors $N_{t+1}^{*}$ and total face value $f_{t+1}^{*}$ are given by

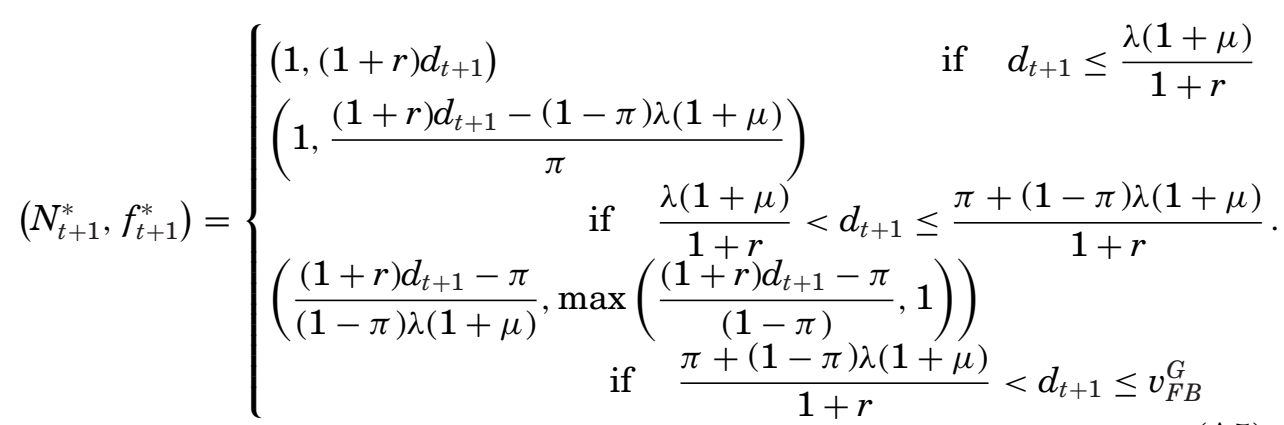

If the realized state is bad $\left(z_{t+1}=1\right)$, then

$$
\begin{aligned}
& \begin{cases}\left(1,(1+r) d_{t+1}\right) & \text { if } \quad d_{t+1} \leq \frac{\lambda}{1+r} \\
\left(1,(1+r) d_{t+1}-(1-\pi)(1-p) \lambda\right.\end{cases} \\
& \left(1, \frac{(1+r) d_{t+1}-(1-\pi)(1-p) \lambda}{\pi+(1-\pi) p}\right) \\
& \text { if } \frac{\lambda}{1+r}<d_{t+1} \leq \frac{\pi \lambda(1+\mu)+(1-\pi)[p(1+\mu)+1-p] \lambda}{1+r} \\
& \left(1, \frac{(1+r) d_{t+1}-(1-\pi)[p \lambda(1+\mu)+(1-p) \lambda]}{\pi}\right) \\
& \text { if } \quad \frac{\pi \lambda(1+\mu)+(1-\pi)[p(1+\mu)+1-p] \lambda}{1+r}<d_{t+1} \leq \\
& \left(N_{t+1}^{*}, f_{t+1}^{*}\right)=\left\{\begin{array}{r}
\frac{\pi+(1-\pi)[p(1+\mu)+1}{1+r} \\
\left.\frac{(1+r) d_{t+1}-\pi}{(1-\pi)[p(1+\mu)+1-p] \lambda}, \max \left(\frac{(1+r) d_{t+1}-\pi}{(1-\pi)\left(p+\frac{1-p}{1+\mu}\right)}, 1\right)\right)
\end{array}\right. \\
& \text { if } \frac{\pi+(1-\pi)[p(1+\mu)+1-p] \lambda}{1+r}<d_{t+1} \leq \\
& \frac{\pi+(1-\pi)[p(1+\mu)+1-p] \kappa^{B}}{1+r} \\
& \left(\frac{(1+r) d_{t+1}-[\pi+(1-\pi)(1-p) \lambda]}{(1-\pi) p \lambda(1+\mu)}, \frac{(1+r) d_{t+1}-[\pi+(1-\pi)(1-p) \lambda]}{(1-\pi) p}\right) \\
& \text { if } \frac{\pi+(1-\pi)[p(1+\mu)+1-p] \kappa^{B}}{1+r}<d_{t+1} \leq \kappa^{B} .
\end{aligned}
$$

Proof of Proposition 2: First, consider the good state. Since the firm is never prematurely terminated, the first-best value $V_{F B}^{G}$ can be achieved. Recall that whenever indifferent, the firm first minimizes the number of creditors and then the face value of debt. The smallest number of creditors is one.

- Case G.1: $d_{t+1} \leq \frac{\lambda(1+\mu)}{1+r}$. The firm can issue debt with normalized face value $f_{t+1}^{*}=(1+r) d_{t+1}$ to a single creditor $N_{t+1}^{*}=1$. If the project matures in period $t+1$, since $f_{t+1}^{*} \leq \lambda(1+\mu)<1$, the creditor will receive the full 
repayment $f_{t+1}^{*} Y_{t+1}$. If the project does not mature, the renegotiated repayment is $\min \left(f_{t+1}^{*} Y_{t+1}, \lambda(1+\mu) Y_{t+1}\right)=f_{t+1}^{*} Y_{t+1}$. Therefore, this debt is risk-free and hence minimizes the face value.

- Case G.2: $\frac{\lambda(1+\mu)}{1+r}<d_{t+1} \leq \frac{\pi+(1-\pi) \lambda(1+\mu)}{1+r}$. It is still possible to borrow from a single creditor: $N_{t+1}^{*}=1$. Solving for the face value $f_{t+1}^{*}$ from the following debt valuation condition gives the smallest face value in the proposition:

$$
d_{t+1}=\frac{1}{1+r}\left[\pi f_{t+1}^{*}+(1-\pi) \lambda(1+\mu)\right] \text {. }
$$

If the project matures, $f_{t+1}^{*} Y_{t+1}<Y_{t+1}$ is repaid since we are in Case G.2. Otherwise, renegotiated payment is $\lambda Y_{t+1}(1+\mu)>f_{t+1}^{*} Y_{t+1}$. Combining these two scenarios gives the value of debt (A7). Hence, $f_{t+1}^{*}=$ $\frac{(1+r) d_{t+1}-(1-\pi) \lambda(1+\mu)}{\pi}$.

- Case G.3: $d_{t+1}>\frac{\pi+(1-\pi) \lambda(1+\mu)}{1+r}$. Because the maximum repayment if the project matures in period $t+1$ is $\pi Y_{t+1}$, and the renegotiated repayment is bounded by $N_{t+1}^{*} \lambda Y_{t+1}(1+\mu)$, creditor dispersion $N_{t+1}^{*}$ must therefore satisfy

$$
d_{t+1} \geq \frac{1}{1+r}\left[\pi+(1-\pi) N_{t+1}^{*} \lambda(1+\mu)\right]
$$

which gives a lower bound of $N^{*} \geq \frac{(1+r) d_{t+1}-\pi}{(1-\pi) \lambda(1+\mu)}$. This lower bound can be attained by setting the face value $f_{t+1}^{*}=\max \left(1, N_{t+1}^{*} \lambda(1+\mu)\right)$.

Next, consider a firm that is currently in a bad state. Since the firm can attain the first-best value in the good state, it is optimal to schedule as much repayment (or equivalently, leverage) as possible in that state.

- Case B.1: $d_{t+1} \leq \frac{\lambda}{1+r}$. Similar to Case G.1 in the good state, the firm can issue risk-free debt with $f_{t+1}^{*}=(1+r) d_{t+1}$ to $N_{t+1}^{*}=1$ creditor.

- Case B.2:

$$
\frac{\lambda}{1+r}<d_{t+1} \leq \frac{1}{1+r}\{\pi \lambda(1+\mu)+(1-\pi)[p(1+\mu)+(1-p)] \lambda\} .
$$

Similar to Case G.2 in the good state, the required leverage can still be sustained with a single creditor $N_{t+1}^{*}=1$, although the debt is no longer risk-free due to renegotiation. To minimize face value in this case, debt is only renegotiated in the bad state to $\lambda Y_{t+1}$, that is, $\lambda Y_{t+1}<$ $F_{t+1}^{*} \leq \lambda Y_{t+1}(1+\mu)$, or equivalently $\lambda<f_{t+1}^{*} \leq \lambda(1+\mu)$. The face value $f_{t+1}^{*}$ solves

$$
d_{t+1}=\frac{1}{1+r}\left\{\pi f_{t+1}^{*}+(1-\pi)\left[p f_{t+1}^{*}+(1-p) \lambda\right]\right\} .
$$

- Case B.3:

$$
\begin{aligned}
& \frac{1}{1+r}\{\pi \lambda(1+\mu)+(1-\pi)[p(1+\mu)+(1-p)] \lambda\}<d_{t+1} \\
& \leq \frac{1}{1+r}\{\pi+(1-\pi)[p(1+\mu)+1-p] \lambda\} .
\end{aligned}
$$


Similar to the previous case, the repayment is renegotiated down to $\lambda Y_{t+1}(1+\mu)$ in the good state and to $\lambda Y_{t+1}$ in the bad state. Therefore, the face value $f_{t+1}^{*} \in(\lambda(1+\mu), 1]$ solves

$$
d_{t+1}=\frac{1}{1+r}\left\{\pi f_{t+1}^{*}+(1-\pi)[p \lambda(1+\mu)+(1-p) \lambda]\right\}
$$

- Case B.4:

$$
\begin{aligned}
& \frac{1}{1+r}\{\pi+(1-\pi)[p(1+\mu)+1-p] \lambda\}<d_{t+1} \\
& \quad \leq \frac{1}{1+r}\left\{\pi+(1-\pi)[p(1+\mu)+1-p] \kappa^{B}\right\} .
\end{aligned}
$$

Since the repayment in the good state is bounded by $1+\mu$ times that in the bad state,

$$
\min \left(F_{t+1}^{*}, N_{t+1}^{*} \lambda Y_{t+1}(1+\mu)\right) \leq(1+\mu) \min \left(F_{t+1}^{*}, N_{t+1}^{*} \lambda Y_{t+1}(1+\mu)\right),
$$

and the repayment when the project matures is bounded by $\pi Y_{t+1}$, the minimum repayment in the bad state (or equivalently, the minimum $N_{t+1}^{*}$ ) solves

$$
d_{t+1}=\frac{1}{1+r}\left\{\pi+(1-\pi)[p(1+\mu)+1-p] \lambda N_{t+1}^{*}\right\} .
$$

This is achieved by a face value $f_{t+1}^{*}=\max \left(1, N_{t+1}^{*} \lambda(1+\mu)\right)$. The renegotiated repayment is $\lambda N_{t+1}^{*} Y_{t+1}(1+\mu)$ in the good state and $\lambda N_{t+1}^{*} Y_{t+1} \leq$ $\kappa^{B} Y_{t+1}$ in the bad state.

- Case B.5: Finally, $d_{t+1}^{*}>\frac{1}{1+r}\left\{\pi+(1-\pi)[p(1+\mu)+1-p] \kappa^{B}\right\}$. From the discussion of (17) in the main text, rollover must fail in the bad state when debt matures in period $t+1$. The renegotiated repayment in the good state is bounded by $N_{t+1}^{*} \lambda Y_{t+1}(1+\mu)$. Therefore, $N_{t+1}^{*}$ solves

$$
d_{t+1}=\frac{1}{1+r}\left[\pi+(1-\pi)\left(p N_{t+1}^{*} \lambda(1+\mu)+(1-p) \lambda\right)\right]
$$

and the corresponding minimum $f_{t+1}^{*}=\max \left(1, N_{t+1}^{*} \lambda(1+\mu)\right)$, completing the proof.

Remark on the additional assumption $\lambda(1+\mu)<1$ : This assumption is made purely to conserve space. If the opposite is true, that is, $\lambda(1+\mu) \geq 1$, then the equilibrium is characterized as follows. If the realized state is good $\left(z_{t+1}=\right.$ $1+\mu)$, then the new number of creditors $N_{t+1}^{*}$ and the total face value $f_{t+1}^{*}$ are given by

$$
\left(N_{t+1}^{*}, f_{t+1}^{*}\right)= \begin{cases}\left(1,(1+r) d_{t+1}\right) & \text { if } d_{t+1} \leq \frac{1}{1+r} \\ \left(1, \frac{(1+r) d_{t+1}-\pi}{1-\pi}\right) & \text { if } \frac{1}{1+r}<d_{t+1} \leq \frac{\pi+(1-\pi) \lambda(1+\mu)}{1+r} \\ \left(\frac{1+r) d_{t+1}-\pi}{(1-\pi) \lambda(1+\mu)}, \frac{(1+r) d_{t+1}-\pi}{(1-\pi)}\right) & \text { if } \frac{\pi+(1-\pi) \lambda(1+\mu)}{1+r}<d_{t+1} \leq v_{F B}^{G}\end{cases}
$$


If the realized state is bad: $z_{t+1}=1$, then

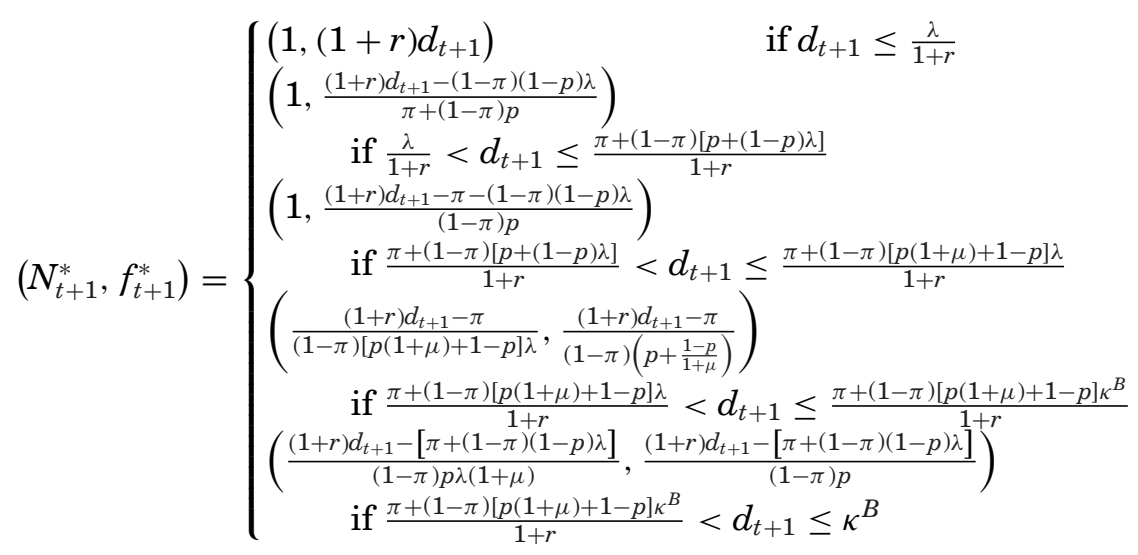

The proof of this case is logically identical to that of Proposition 2.

Proof of Corollary 2: First, consider the good state, $z_{t+1}=1+\mu$. If $d_{t+1}$ belongs to Cases G.1 or G.2 in the proof of Proposition 2, then $N_{t+1}^{*}=1 \leq N_{t}^{*}$ and the conclusion $N_{t+1}^{*} \leq N_{t}^{*}$ holds trivially. Otherwise, $d_{t+1}$ belongs to Case G.3, and $N_{t+1}^{*}=\frac{(1+r) d_{t+1}-\pi}{(1-\pi) \lambda(1+\mu)}$. Recall that

$$
d_{t+1} \leq v_{F B}^{G}=\frac{\pi}{1+r-(1-\pi)(1+\mu)},
$$

which implies

$$
\frac{(1+r) d_{t+1}-\pi}{(1-\pi) \lambda(1+\mu)} \leq \frac{d_{t+1}}{\lambda}
$$

Together with the fact that $d_{t+1}=\min \left(\frac{f_{t}}{z_{t+1}}, N_{t}^{*} \lambda\right) \leq N_{t}^{*} \lambda$, we have

$$
N_{t+1}^{*}=\frac{(1+r) d_{t+1}-\pi}{(1-\pi) \lambda(1+\mu)} \leq \frac{d_{t+1}}{\lambda} \leq N_{t}^{*}
$$

Next, I study the bad state, $z_{t+1}=1$. Clearly, if $N_{t}^{*}=1$, the result $N_{t+1}^{*} \geq N_{t}^{*}$ holds trivially. Now consider $N_{t}^{*}>1$. Because debt rollover is still possible in period $t$ with $z_{t+1}=1$, Proposition 2 suggests that $N_{t}^{*}$ must belong to Case B.4 in the proof of Proposition 2. Hence, we have

$$
\begin{gathered}
N_{t}^{*}=\frac{(1+r) d_{t}-\pi}{(1-\pi)[p(1+\mu)+1-p] \lambda} \leq \frac{\kappa^{B}}{\lambda}, \\
d_{t} \leq \frac{1}{1+r}\left\{\pi+(1-\pi)[p(1+\mu)+1-p] \kappa^{B}\right\}, \\
d_{t}>\frac{1}{1+r}\{\pi+(1-\pi)[p(1+\mu)+1-p] \lambda\},
\end{gathered}
$$


and

$$
(1+r) d_{t}=\pi+(1-\pi)[p(1+\mu)+1-p] d_{t+1},
$$

where $d_{t+1}=\min \left(f_{t}, \lambda N_{t}^{*}\right)=\lambda N_{t}^{*}$ is the actual amount of leverage refinanced in the bad state $\left(z_{t+1}=1\right)$ in period $t$.

There are two possibilities, which I consider in turn.

Case 1: If the project is not sold in period $t+1$ following a bad state $\left(z_{t+2}=\right.$ 1 ), then both $N_{t+1}^{*}=\frac{(1+r) d_{t+1}-\pi}{(1-\pi)[p(1+\mu)+1-p] \lambda}$ and $N_{t}^{*}$ belong to Case B.4. Hence, it is sufficient to show that $d_{t+1}>d_{t}$. Denote by $\hat{d}$ the solution to

$$
\hat{d}=\frac{1}{1+r}\{\pi+(1-\pi)[p(1+\mu)+1-p] \hat{d}\} .
$$

Subtracting (A14) from (14) yields

$$
\lambda-\hat{d}>\frac{1}{1+r}\{\pi+(1-\pi)[p(1+\mu)+1-p](\lambda-\hat{d})\},
$$

which is equivalent to

$$
\{1+r-(1-\pi)[p(1+\mu)+1-p]\}(\lambda-\hat{d})>\frac{\pi}{1+r} .
$$

Because

$$
1+r>(1-\pi)(1+\mu)>(1-\pi)[p(1+\mu)+1-p],
$$

(A15) implies that $\lambda>\hat{d}$. Consequently,

$$
\begin{aligned}
& \frac{1}{1+r}\{\pi+(1-\pi)[p(1+\mu)+1-p] \lambda\} \\
& \quad>\frac{1}{1+r}\{\pi+(1-\pi)[p(1+\mu)+1-p] \hat{d}\}=\hat{d}
\end{aligned}
$$

and as a result, (A12) implies that

$$
d_{t}>\hat{d}
$$

It then follows from (A14) and (A13) that

$$
0<(1+r)\left(d_{t}-\hat{d}\right)=(1-\pi)[p(1+\mu)+1-p]\left(d_{t+1}-\hat{d}\right) .
$$

Using (A16), it follows that $d_{t}-\hat{d}<d_{t+1}-\hat{d}$, and therefore $d_{t}<d_{t+1}$ and $N_{t+1}^{*}>N_{t}^{*}$.

Case 2: If the project is sold in period $t+1$ following a bad state, then $N_{t+1}^{*}=\frac{(1+r) d_{t+1}-[\pi+(1-\pi)(1-p) \lambda]}{(1-\pi) p \lambda(1+\mu)}$ belongs to Case B.5 in (A6). From the lower bound 
of $d_{t+1} \geq \frac{\pi+(1-\pi)[p(1+\mu)+1-p] \kappa^{B}}{1+r}$ in this case, we have

$$
\begin{aligned}
N_{t+1}^{*} & \geq \frac{(1+r) \frac{\pi+(1-\pi)[p(1+\mu)+1-p] \kappa^{B}}{1+r}-[\pi+(1-\pi)(1-p) \lambda]}{(1-\pi) p \lambda(1+\mu)} \\
& =\frac{[p(1+\mu)+1-p] \kappa^{B}-(1-p) \lambda}{p \lambda(1+\mu)} .
\end{aligned}
$$

Using the fact that $\kappa^{B}>\lambda$, we have

$$
N_{t+1}^{*} \geq \frac{[p(1+\mu)+1-p] \kappa^{B}-(1-p) \lambda}{p \lambda(1+\mu)}>\frac{\kappa^{B}}{\lambda} \geq N_{t}^{*},
$$

where the second inequality follows from (A10). This completes the proof.

Proof of Corollary 3: The debt capacities in (15) and (16) are increasing in $\mu$, establishing the first statement in the corollary.

To prove the second statement, I discuss two cases depending on whether the shared refinancing leverage $d_{t+1}$ belongs to the same case in the proof of Proposition 2. (Note that the cutoffs between cases depend on the parameter u.)

Case 1: For both firms, $d_{t+1}$ falls into the same case. It is easy to check that within each of these cases, $N_{t+1}^{*}$ is decreasing in $\mu$.

Case 2: $d_{t+1}$ falls into different cases as $\mu$ varies. Because the cutoffs between cases are increasing in $\mu$, the case that $d_{t+1}$ falls into under the firm type $\mu_{2}$ must precede that under $\mu_{1}$. Since $N_{t+1}^{*}$ is weakly increasing across cases, we have $N_{t+1}^{*}\left(\mu_{1}\right) \geq N_{t+1}^{*}\left(\mu_{2}\right)$.

Proof of Prediction 1: First, note that $N_{t+1}^{*}$ in all possibilities-(A5), (A6), (A8), and (A9) - is weakly increasing in $d_{t+1}$. The monotonicity is strict whenever $N_{t+1}^{*}>1$.

When $\lambda(1+\mu) \geq 1$, it is easy to check from (A8) and (A9) that the ratio $\frac{f_{t+1}^{*}}{d_{t+1}}=$ $\frac{F_{t+1}^{*}}{D_{t+1}}$ takes the form $c_{1}-\frac{c_{2}}{d_{t+1}}$, where $c_{1}$ and $c_{2}$ are nonnegative constants (strictly positive whenever the debt is not risk-free). Therefore, this ratio is increasing in $d_{t+1}$ and the creditor dispersion $N_{t+1}^{*}$ covaries positively with the interest rate $\frac{F_{t+1}^{*}}{D_{t+1}}$ in equilibrium.

When $\lambda(1+\mu)<1$, the assumption that $N_{t+1}^{*} \geq \frac{1}{\lambda(1+\mu)}$ implies that in the good state, creditor structure falls into the third case in (A5) and $F_{t+1}^{*}=$ $N_{t+1}^{*} \lambda(1+\mu) Y_{t+1} \geq Y_{t+1}$. Similarly, in a bad state, creditor structure falls into the fourth or fifth cases in (A6) and $F_{t+1}^{*}=N_{t+1}^{*} \lambda(1+\mu) Y_{t+1} \geq Y_{t+1}$ again holds. Therefore, in each one of the aforementioned cases, the ratio $\frac{f_{t+1}^{*}}{d_{t+1}}=\frac{F_{t+1}^{*}}{D_{t+1}}$ takes the form $c_{1}-\frac{c_{2}}{d_{t+1}}$, where $c_{1}$ and $c_{2}$ are positive constants. The same argument for the previous case $\lambda(1+\mu) \geq 1$ establishes the result.

Proof of Proposition 3: First, consider the good state $z_{t}=1+\mu \Delta t$ in period $t$. If the project matures, then the total repayment is at most $Y_{t}$. If the 
project does not mature, then with $N$ creditors, the maximum repayment that can be refinanced is

$$
\min \left(\hat{\kappa}_{N}^{G}(1+\mu \Delta t) Y_{t}, N \lambda(1+\mu \Delta t) Y_{t}\right)=\min \left(\hat{\kappa}_{N}^{G}, N \lambda\right)(1+\mu \Delta t) Y_{t} .
$$

Hence, the ex ante value of debt at time $t$ is bounded by

$$
\frac{1}{1+r \Delta t}\left[\pi \Delta t+(1-\pi \Delta t) \min \left(\hat{\kappa}_{N}^{G}, N \lambda\right)(1+\mu \Delta t)\right] Y_{t}
$$

There are two cases, depending on the size of $N$.

Case 1: $N>\frac{\hat{v}_{F B}^{G}}{\lambda}$. In this case, setting the face value at $F_{t}=\max \left(1, \hat{v}_{F B}^{G}(1+\right.$ $\mu \Delta t)) Y_{t} \in\left[Y_{t}, N \lambda Y_{t+\Delta t}\right)$, the firm has incentive to pay $F_{t}$ if the project does not mature. The value of debt is

$$
\frac{1}{1+r \Delta t}\left[\pi \Delta t Y_{t}+(1-\pi \Delta t) \hat{v}_{F B}^{G}(1+\mu \Delta t) Y_{t}\right]=\hat{v}_{F B}^{G} Y_{t},
$$

where the equality is the recursive definition of the first-best value in (24). Since $\hat{v}_{F B}^{G}$ is already the first-best firm value, the debt capacity is indeed $\hat{\kappa}_{N}^{G}=$ $\hat{v}_{F B}^{G}$.

Case 2: $N \leq \frac{\hat{v}_{F B}^{G}}{\lambda}$. I first show that $\lambda N \leq \hat{\kappa}_{N}^{G}$, meaning that the renegotiated payment of $N \lambda Y_{t+\Delta t}$ can be refinanced into period $t+\Delta t$ with $N$ creditors. Suppose otherwise, that $\lambda N>\hat{\kappa}_{N}^{G}$. By setting the face value to $F_{t}=$ $\max \left(1, \hat{\kappa}_{N}^{G}(1+\mu \Delta t)\right) Y_{t}$, the value of debt can attain

$$
\frac{1}{1+r \Delta t}\left[\pi \Delta t+(1-\pi \Delta t) \hat{\kappa}_{N}^{G}(1+\mu \Delta t)\right] Y_{t},
$$

which, by the definition of debt capacity, is bounded by $\hat{\kappa}_{N}^{G} Y_{t}$ :

$$
\frac{1}{1+r \Delta t}\left[\pi \Delta t+(1-\pi \Delta t) \hat{\kappa}_{N}^{G}(1+\mu \Delta t)\right] \leq \hat{\kappa}_{N}^{G}
$$

Because $\frac{(1-\pi \Delta t)(1+\mu \Delta t)}{1+r \Delta t}<1$, condition (A18) implies that $\hat{\kappa}_{N}^{G} \geq \hat{v}_{F B}^{G}$, which in turn dominates $\lambda N$ since we are in Case 2. This contradiction establishes $\lambda N \leq \hat{\kappa}_{N}^{G}$. Hence, (A17) becomes

$$
\frac{1}{1+r \Delta t}[\pi \Delta t+(1-\pi \Delta t) N \lambda(1+\mu \Delta t)] Y_{t},
$$

concluding the proof for the good state.

Next, consider the bad state $z_{t}=1$. I first show that to achieve the debt capacity $\hat{\kappa}_{N}^{B}$, debt rollover must fail should the bad state persist, that is, $z_{t+\Delta t}=$ 1. Suppose otherwise, that the debt capacity is attained by having successful rollover in both states:

$$
\widehat{\kappa}_{N}^{B} Y_{t}=\frac{1}{1+r \Delta t}\left\{\pi \Delta t Y_{t}+(1-\pi \Delta t)\left[p \Delta t \min \left(N \lambda Y_{t}(1+\mu \Delta t), F_{t}\right)\right)\right)
$$




$$
\left(\left(+(1-p \Delta t) \min \left(N \lambda Y_{t}, F_{t}\right)\right]\right\} .
$$

Clearly, for rollover to be successful, it must be the case that

$$
\min \left(N \lambda Y_{t}, F_{t}\right) \leq \hat{\kappa}_{N}^{B} Y_{t}
$$

Hence, the repayment in the good state must be bounded by

$$
\min \left(N \lambda Y_{t}(1+\mu \Delta t), F_{t}\right) \leq \min \left(N \lambda Y_{t}, F_{t}\right)(1+\mu \Delta t) \leq(1+\mu \Delta t) \hat{\kappa}_{N}^{B} Y_{t} .
$$

We therefore have

$$
\hat{\kappa}_{N}^{B} \leq \frac{1}{1+r \Delta t}\left\{\pi \Delta t+(1-\pi \Delta t)[p \Delta t(1+\mu \Delta t)+1-p \Delta t] \hat{\kappa}_{N}^{B}\right\} .
$$

Parameter condition (14) implies that

$$
\lambda>\frac{\pi}{1+r-(1-\pi)(\mu p+1)}>\frac{\pi}{1+r-(1-\pi)}=\frac{\pi}{r+\pi},
$$

which in turn implies that for all sufficiently small $\Delta t$, we have

$$
\lambda>\frac{1}{1+r \Delta t}\{\pi \Delta t+(1-\pi \Delta t)[p \Delta t(1+\mu \Delta t)+1-p \Delta t] \lambda\} .
$$

This is because (A21) is equivalent to

$$
\begin{aligned}
& \lambda>\frac{\pi \Delta t}{1+r \Delta t-(1-\pi \Delta t)[(1+\mu \Delta t) p \Delta t+1-p \Delta t]} \\
& =\frac{\pi \Delta t}{1+r \Delta t-(1-\pi \Delta t)\left[1+\mu p(\Delta t)^{2}\right]}
\end{aligned}
$$

and when $\Delta t \rightarrow 0$, the right-hand side approaches $\frac{\pi}{r+\pi}$ in which case this condition becomes (A20). Taking the difference between (A21) and (A19) and using the fact that $1+r \Delta t>(1-\pi \Delta t)(1+\mu \Delta t)$, we have $\hat{\kappa}_{N}^{B}<\lambda$. Since rollover must be successful by assumption, the condition $\min \left(N \lambda Y_{t}, F_{t}\right) \leq \hat{\kappa}_{N}^{B} Y_{t}<\lambda Y_{t}$ holds in the bad state. However, the ex-ante value of debt can be strictly improved by raising $F_{t}=Y_{t}$, and the payoff in the bad state can improve to $\lambda Y_{t}$ through termination - a contradiction. Hence, the debt capacity $\hat{\kappa}_{N}^{B} Y_{t}$ must be achieved by having termination in the bad state.

Clearly, the maximum repayment if the project matures is $Y_{t}$, which is achieved by any face value $F_{t} \geq Y_{t}$. Next, I determine the repayment to debt holders when the bad state switches to a good one, that is, $z_{t+\Delta t}=1+\mu \Delta t$.

As shown before, when $N \leq \frac{\hat{v}_{F B}^{G}}{\lambda}$, the renegotiated repayment of $\lambda N Y_{t}(1+$ $\mu \Delta t) \leq \hat{\kappa}_{N}^{G} Y_{t}(1+\mu \Delta t)$ can be refinanced by $N$ creditors. Therefore, the debt capacity is achieved by setting $F_{t}=\max (1,(1+\mu \Delta t) N \lambda) Y_{t}$ and

$$
\hat{\kappa}_{N}^{B}=\frac{1}{1+r \Delta t}\{\pi \Delta t+(1-\pi \Delta t)[p \Delta t(1+\mu \Delta t) N+1-p \Delta t] \lambda\} .
$$


In contrast, when $N>\frac{\hat{0}_{F B}^{G}}{\lambda}$, the repayment that can be refinanced in the good state is bounded by $\hat{v}_{F B}^{G} Y_{t}(1+\mu \Delta t)$, which is attained by having the face value set at the same level. As a result, the debt capacity is given by

$$
\hat{\kappa}_{N}^{B}=\frac{1}{1+r \Delta t}\left\{\pi \Delta t+(1-\pi \Delta t)\left[p \Delta t(1+\mu \Delta t) \hat{v}_{F B}^{G}+(1-p \Delta t) \lambda\right]\right\} .
$$

Combining (A22) and (A23), we have

$$
\begin{array}{r}
\widehat{\kappa}_{N}^{B}=\frac{1}{1+r \Delta t}\{\pi \Delta t) \\
\left(+(1-\pi \Delta t)\left[p \Delta t(1+\mu \Delta t) \max \left(\widehat{v}_{F B}^{G}, \lambda N\right)+(1-p \Delta t) \lambda\right]\right\},
\end{array}
$$

establishing all equations in Proposition 3.

Proof of Proposition 4: As established by expression (24), the limit of $\hat{v}_{F B}^{G}$ as $\Delta t \rightarrow 0$ is finite (specifically, $\frac{\pi}{r-\mu+\pi}$ ). Hence, it follows immediately from (28) that $\hat{\kappa}_{N}^{B} \rightarrow \lambda$ as $\Delta t \rightarrow 0$. Next, I turn to the total debt capacity in the bad state. Since the parameter assumption (A21) holds (the $\Delta t$ analogue of (14)), the debt capacity given by (29) is a direct consequence of Proposition 1. Finally, it is obvious that $\hat{\kappa}^{B}$ in (29) approaches $\lambda$ as $\Delta t \rightarrow 0$, completing the proof.

Proof of Proposition 5: Suppose $N_{t}=1$. I show that the modified refinancing strategies $\hat{C}_{t}=0$ and $\hat{F}_{t}=F_{t}-C_{t}$ implement the same payoff to both the firm and the creditor in each period. First, the net amount that must be refinanced in period $t$ is

$$
\min \left(F_{t}, L_{t}+C_{t}\right)-C_{t}=\min \left(\hat{F}_{t}, L_{t}+\hat{C}_{t}\right)-\hat{C}_{t}
$$

Thus, the continuation game (35) in period $t$ is not affected.

Second, the debt rollover outcome in period $t-1$ is not affected by the modification. This is because the modified value of debt (31) is

$$
\begin{aligned}
\widehat{D}_{t}= & \frac{1}{1+r}\left\{\pi \min \left(\widehat{F}_{t}, Y_{t}\right)\right) \\
& \quad\left(+(1-\pi) E_{t}\left[\mathbf{1}_{R O} \min \left(\widehat{F}_{t}, L_{t}\right)+\left(1-\mathbf{1}_{R O}\right) \min \left(\widehat{F}_{t}, L_{t}\right)\right]\right\} \\
= & D_{t}-\frac{C_{t}}{1+r} .
\end{aligned}
$$

So the net repayment to creditors maturing in period $t-1$ is the same,

$$
\hat{D}_{t}-\frac{\hat{C}_{t}}{1+r}=D_{t}-\frac{C_{t}}{1+r},
$$

and condition (35) in period $t-1$ is therefore unaffected. 
Finally, the equity value $\hat{V}_{t}$ at the end of period $t-1$ is also unaffected by the modification. By definition

$$
\hat{F}_{t}-\hat{C}_{t}=F_{t}-C_{t}
$$

and therefore the expression in (34) stays the same. In summary, the equilibrium can be implemented by setting $C_{t}=0$, completing the proof.

Proof of Proposition 6: Define $\hat{F}_{t}=F_{t}-C_{t}$ and $\hat{D}_{t}=D_{t}-\frac{C_{t}}{1+r}$. The value of debt in (31) becomes

$$
\begin{array}{r}
\widehat{D}_{t}\left(\widehat{F}_{t}, N_{t}, C_{t}\right)=\frac{1}{1+r}\left\{\pi \min \left(\widehat{F}_{t}, Y_{t}\right)+(1-\pi)\right) \\
\left(E_{t}\left[\mathbf{1}_{R O} \min \left(\widehat{F}_{t}, N_{t} \lambda Y_{t+1}+\left(N_{t}-1\right) C_{t}\right)+\left(1-\mathbf{1}_{R O}\right) \min \left(\widehat{F}_{t}, L_{t}\right)\right]\right\}
\end{array}
$$

with the rollover condition (33):

$$
\min \left(\hat{F}_{t}, N_{t} \lambda Y_{t+1}+\left(N_{t}-1\right) C_{t}\right) \leq D C_{t+1}
$$

First, in equilibrium, it must be the case that

$$
\hat{F}_{t} \leq N_{t} \lambda(1+\mu) Y_{t}+\left(N_{t}-1\right) C_{t} .
$$

Otherwise, the firm can lower $\hat{F}_{t}$ to $N_{t} \lambda(1+\mu) Y_{t}+\left(N_{t}-1\right) C_{t}$ without affecting the actual debt repayment, contradicting with the minimality of $\hat{F}_{t}$. As a result of (A25), the net repayment in the good state is $\hat{F}_{t}$.

Second, I show that having termination in the good state is not optimal, that is, $\hat{F}_{t} \leq D C_{t+1}^{G}$. Suppose otherwise. From (A25), we know that

$$
N_{t} \lambda(1+\mu) Y_{t}+\left(N_{t}-1\right) C_{t} \geq \hat{F}_{t}>D C_{t+1}^{G} .
$$

If termination also happens in the bad state, then obviously the values of debt and equity can both be improved by reducing $\hat{F}_{t}$ to $D C_{t+1}^{G}$. Hence,

$$
\min \left(\hat{F}_{t}, N_{t} \lambda Y_{t}+\left(N_{t}-1\right) C_{t}\right) \leq D C_{t+1}^{B}
$$

In the good state, the firm can pledge the entire first-best firm value as in the baseline model without cash. Therefore, $D C_{t+1}^{G}=v_{F B}^{G} Y_{t}(1+\mu)$. The debt capacity in the bad state must be bounded by the first-best value. Hence, $D C_{t+1}^{B} \leq v_{F B}^{B} Y_{t}<D C_{t+1}^{G}$. Recall from (A26) that $\hat{F}_{t}>D C_{t+1}^{G}$, so (A27) implies that

$$
D C_{t+1}^{B} \geq N_{t} \lambda Y_{t}+\left(N_{t}-1\right) C_{t} .
$$

Hence, $D C_{t+1}^{B} \geq \lambda N_{t} Y_{t}$. However, taking the difference between (A26) and (A28), we have

$$
\lambda N_{t} \mu Y_{t}>D C_{t+1}^{G}-D C_{t+1}^{B} \geq v_{F B}^{G}(1+\mu) Y_{t}-v_{F B}^{B} Y_{t}>v_{F B}^{B} \mu Y_{t} \geq D C_{t+1}^{B} \mu Y_{t} .
$$


The contradiction implies that $\hat{F}_{t} \leq D C_{t+1}^{G}$.

Finally, consider a new set of refinancing strategies in period $t-1: N_{t}^{\prime}=$ $N_{t}+\frac{\left(N_{t}-1\right) C_{t}}{L_{t}^{B}}, \hat{F}_{t}^{\prime}=\hat{F}_{t}$, and no cash $C_{t}^{\prime}=0$. It is easy to verify that

$$
N_{t}^{\prime} L_{t}^{B}+\left(N_{t}^{\prime}-1\right) C_{t}^{\prime}=N_{t} L_{t}^{B}+\left(N_{t}-1\right) C_{t}
$$

and

$$
N_{t}^{\prime} L_{t}^{G}+\left(N_{t}-1\right) C_{t}^{\prime}=N_{t} L_{t}^{G}+\frac{\left(N_{t}-1\right) C_{t}}{L_{t}^{B}} L_{t}^{G}>N_{t} L_{t}^{G}+\left(N_{t}-1\right) C_{t} \geq \hat{F}_{t}^{\prime}
$$

Hence, the creditor structure $\left(N_{t}^{\prime}, \hat{F}_{t}^{\prime}, C_{t}^{\prime}\right)$ does not affect the actual repayment to creditors in (A24) in either the good state or the bad state, and the equilibrium outcome can therefore be implemented without cash.

\section{Appendix B: A Static Benchmark}

In this appendix, I present a static version of the dynamic model in Section I to show that statement 2 in Corollary 3 is effectively static, and this static model cannot produce some of the key dynamic intuitions.

There are three dates, $t=0,1,2$, and there is no time discount. At date 0 , the firm chooses the face value of debt $F_{1}$ and creditor dispersion $N_{1}$ to finance a project. The upfront investment is $I_{0}$, and the project generates a final dividend only at date 2 . At date 1 , the state $Y_{1} \in\{1, \mu>1\}$ realizes with $\operatorname{Prob}\left(Y_{1}=\mu\right)=$ $p$ and the resale value $L_{1}=\lambda Y_{1}$. The renegotiation game at date 1 is exactly the same as in the dynamic model in Section I. The final dividend $Y_{2}$ depends on $Y_{1}$ :

$$
Y_{2}=\left\{\begin{array}{ll}
1 & \text { if } Y_{1}=1 \\
\mu^{2} & \text { if } Y_{1}=\mu
\end{array},\right.
$$

that is, in the good state, the fundamental grows by $\mu$, or otherwise there is no growth. For simplicity, I assume that the entire $Y_{2}$ can be pledged at date 1 to repay the maturing debt if the firm has incentive to do so. The optimization problem for the firm is to design $\left(N_{1}, F_{1}\right)$ efficiently at date 0 to finance $I_{0}$.

Proposition B1: Assume that $\mu^{2} p+(1-p) \lambda>\mu p+1-p$. The optimal number of creditors $N_{1}^{*}$ and face value $F_{1}^{*}$ are given by

$$
\left(N_{1}^{*}, F_{1}^{*}\right)= \begin{cases}\left(1, \max \left(I_{0}, \frac{I_{0}-(1-p) \lambda}{p}\right)\right) & \text { if } I_{0} \leq \lambda(\mu p+1-p) \\ \left.\frac{I_{0}}{\lambda(\mu p+1-p)}, \frac{I_{0} \mu}{\mu p+1-p}\right) & \text { if } \lambda(\mu p+1-p)<I_{0} \leq \mu p+1-p \\ \left(\frac{I_{0}-(1-p) \lambda}{\lambda \mu p}, \frac{I_{0}-(1-p) \lambda}{p}\right) & \text { if } \mu p+1-p<I_{0} \leq \mu^{2} p+(1-p) \lambda .\end{cases}
$$


Proof of Proposition B1: If $I_{0} \leq \lambda(\mu p+1-p)$, the firm can be financed without termination in period 1 . When $N_{1}^{*}=1$, if $I_{0} \leq \lambda$, then the debt is riskfree with $F_{1}^{*}=I_{0}$. Otherwise, if $\lambda<I_{0} \leq \lambda(\mu p+1-p)$, the firm renegotiates the payment down to $\lambda$ in the bad state and $F_{1}^{*}=\frac{I_{0}-(1-p) \lambda}{p}$ satisfies the lender's break-even condition,

$$
p F_{1}^{*}+(1-p) \lambda=I_{0} .
$$

To minimize creditor dispersion when $N_{1}^{*}>1$, it must solve

$$
N_{1}^{*} \lambda(\mu p+1-p)=I_{0} .
$$

The corresponding face value is $F_{1}^{*}=N_{1}^{*} \lambda \mu$.

If $I_{0}>\mu p+1-p$, then the firm can only raise investment by risking termination in the bad state $\left(Y_{1}=1\right)$. In this case, the face value again solves (A30), although unlike when $N_{1}^{*}=1$, here the repayment of $\lambda$ in the bad state is through termination. To support $F_{1}^{*}=\frac{I_{0}-(1-p) \lambda}{p}$, the corresponding number of creditors is $N_{1}^{*}=\frac{F_{1}^{*}}{\lambda \mu}$.

When the upfront investment $I_{0}$ is low, the debt is risk-free. As $I_{0}$ increases, the required pledgeability increases, as does $N_{1}^{*}$. In this static model, the growth rate $\mu$ negatively correlates with the required number of creditors $N_{1}^{*}$ for any given financing size $I_{0}$. The intuition is similar to statement 2 in Corollary 3: firms with higher asset growth can pledge more to each creditor because of a higher final dividend in the good state, and therefore do not need as many creditors as lower-growth firms do. One may be tempted to conclude that higher-growth firms should have fewer creditors. This conclusion can be misleading. In the dynamic model, higher-growth firms can survive longer and support more creditors in the long run due to their higher debt capacity. Hence, the equilibrium can feature a positive correlation between a firm's number of creditors and growth rate.

Finally, consider a reduction in the probability of the good outcome, $p$. This exercise is the static version of the dynamic analysis in Section IV.B. Similar to the finding in Proposition 4 , when $p$ decreases, the debt capacity $\mu^{2} p+(1-p) \lambda$ as in (A29) also decreases because the termination payoff $\lambda$ is more likely to occur. However, unlike the model in the main text, where total firm value is held constant as the renegotiation frequency changes, here the ex ante firm value $\mu^{2} p+1-p$ is decreasing in $p$. Hence, in this static model, the reduction of debt capacity is a mechanical result of lower firm quality.

\section{REFERENCES}

Almeida, Heitor, Murillo Campello, Bruno Laranjeira, and Scott Weisbenner, 2012, Corporate debt maturity and the real effects of the 2007 credit crisis, Critical Finance Review 1, 3-58.

Berglöf, Erik, and Ernst-Ludwig Von Thadden, 1994, Short-term versus long-term interests: Capital structure with multiple investors, Quarterly Journal of Economics 109, 1055-1084.

Bolton, Patrick, and David S. Scharfstein, 1996, Optimal debt structure and the number of creditors, Journal of Political Economy 104, 1-25. 
Bris, Arturo, and Ivo Welch, 2005, The optimal concentration of creditors, Journal of Finance 60, 2193-2212.

Brunner, Antje, and Jan Pieter Krahnen, 2008, Multiple lenders and corporate distress: Evidence on debt restructuring, Review of Economic Studies 75, 415-442.

Brunnermeier, Markus K., and Martin Oehmke, 2013, The maturity rat race, Journal of Finance 68, 483-521.

Calomiris, Charles W., and Charles M. Kahn, 1991, The role of demandable debt in structuring optimal banking arrangements, American Economic Review 497-513.

Cheng, Ing-Haw, and Konstantin Milbradt, 2012, The hazards of debt: Rollover freezes, incentives, and bailouts, Review of Financial Studies 25, 1070-1110.

Countryman, Vern, 1985, The concept of a voidable preference in bankruptcy, Vanderbilt Law Review 38, 713.

Detragiache, Enrica, Paolo Garella, and Luigi Guiso, 2000, Multiple versus single banking relationships: Theory and evidence, Journal of Finance 55, 1133-1161.

Diamond, Douglas W., 2004, Presidential address, committing to commit: Short-term debt when enforcement is costly, Journal of Finance 59, 1447-1479.

Diamond, Douglas W., and Philip H. Dybvig, 1983, Bank runs, deposit insurance, and liquidity, Journal of Political Economy 91, 401-419.

W Diamond, Douglas, and Raghuram G. Rajan, 2001, Liquidity risk, liquidity creation, and financial fragility: A theory of banking, Journal of Political Economy 109, 287-327.

Farinha, Luısa A., and Joao A.C. Santos, 2002, Switching from single to multiple bank lending relationships: Determinants and implications, Journal of Financial Intermediation 11, 124151.

Gilson, Stuart C., Kose John, and Larry H.P. Lang, 1990, Troubled debt restructurings: An empirical study of private reorganization of firms in default, Journal of Financial Economics 27, $315-353$.

Goldstein, Itay, and Ady Pauzner, 2005, Demand-deposit contracts and the probability of bank runs, Journal of Finance 60, 1293-1327.

Harhoff, Dietmar, and Timm Körting, 1998, Lending relationships in germany-empirical evidence from survey data, Journal of Banking and Finance 22, 1317-1353.

Hart, Oliver, and John Moore, 1998, Default and renegotiation: A dynamic model of debt, Quarterly Journal of Economics 113, 1-41.

He, Zhiguo, and Wei Xiong, 2012a, Dynamic debt runs, Review of Financial Studies 25, 1799-1843.

He, Zhiguo, and Wei Xiong, 2012b, Rollover risk and credit risk, Journal of Finance 67, 391-430.

Hege, Ulrich, and Pierre Mella-Barral, 2005, Repeated dilution of diffusely held debt, Journal of Business 78, 737-786.

Hertzberg, Andrew, Jose Maria Liberti, and Daniel Paravisini, 2011, Public information and coordination: Evidence from a credit registry expansion, Journal of Finance 66, 379-412.

Houston, Joel, and Christopher James, 1996, Bank information monopolies and the mix of private and public debt claims, Journal of Finance 51, 1863-1889.

Huang, Chong ,Martin Oehmke, and Hongda Zhong, 2019, A theory of multiperiod debt structure, The Review of Financial Studies 32, 4447-4500. https://doi.org/10.1093/rfs/hhz026.

Leland, Hayne E., 1994, Corporate debt value, bond covenants, and optimal capital structure, Journal of Finance 49, 1213-1252.

McCoid, John C., 1981, Bankruptcy, preferences, and efficiency: An expression of doubt, Virginia Law Review 249-273.

Mella-Barral, Pierre, 1999, The dynamics of default and debt reorganization, Review of Financial Studies 12, 535-578.

Mella-Barral, Pierre, and William Perraudin, 1997, Strategic debt service, Journal of Finance 52, $531-556$.

Ongena, Steven, and David C. Smith, 2000a, Bank relationships: A review, Performance of Financial Institutions: Efficiency, Innovation, Regulation 221-258.

Ongena, Steven, and David C. Smith, 2000b, What determines the number of bank relationships? Cross-country evidence, Journal of Financial Intermediation 9, 26-56. 
Petersen, Mitchell A., and Raghuram G. Rajan, 1994, The benefits of lending relationships: Evidence from small business data, Journal of Finance 49, 3-37.

Petersen, Mitchell A., and Raghuram G. Rajan, 1995, The effect of credit market competition on lending relationships, Quarterly Journal of Economics 110, 407-443.

Rauh, Joshua D., and Amir Sufi, 2010, Capital structure and debt structure, Review of Financial Studies 23, 4242-4280.

Roberts, Michael R., 2015, The role of dynamic renegotiation and asymmetric information in financial contracting, Journal of Financial Economics 116, 61-81.

Roberts, Michael R., and Amir Sufi, 2009a, Control rights and capital structure: An empirical investigation, Journal of Finance 64, 1657-1695.

R Roberts, Michael, and Amir Suf, 2009b, Renegotiation of financial contracts: Evidence from private credit agreements, Journal of Financial Economics 93, 159-184.

Zetlin-Jones, Ariel, 2014, Efficient financial crises, in 2014 Meeting Papers, number 880, Society for Economic Dynamics.

Zhong, Hongda, and Zhen Zhou, 2020, Dynamic runs and optimal termination, Working Paper, Department of Finance, the London School of Economics and Political Science; PBC School of Finance, Tsinghua University.

\section{Supporting Information}

Additional Supporting Information may be found in the online version of this article at the publisher's website:

\section{Replication code.}

